Universidad de Lima

Escuela de Posgrado

Maestría en Tributación y Política Fiscal

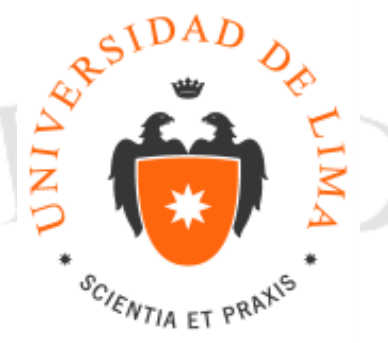

\title{
LA DOBLE NO IMPOSICIÓN EN APLICACIÓN DE LOS CONVENIOS PARA EVITAR LA DOBLE IMPOSICIÓN
}

Trabajo de investigación para optar el Grado Académico de Maestro en

Tributación y Política Fiscal

\section{Alfredo Adolfo Blas Cervantes}

Código 20132464

Asesor

Fernando Núñez Ciallella

Lima - Perú

Marzo, 2018 


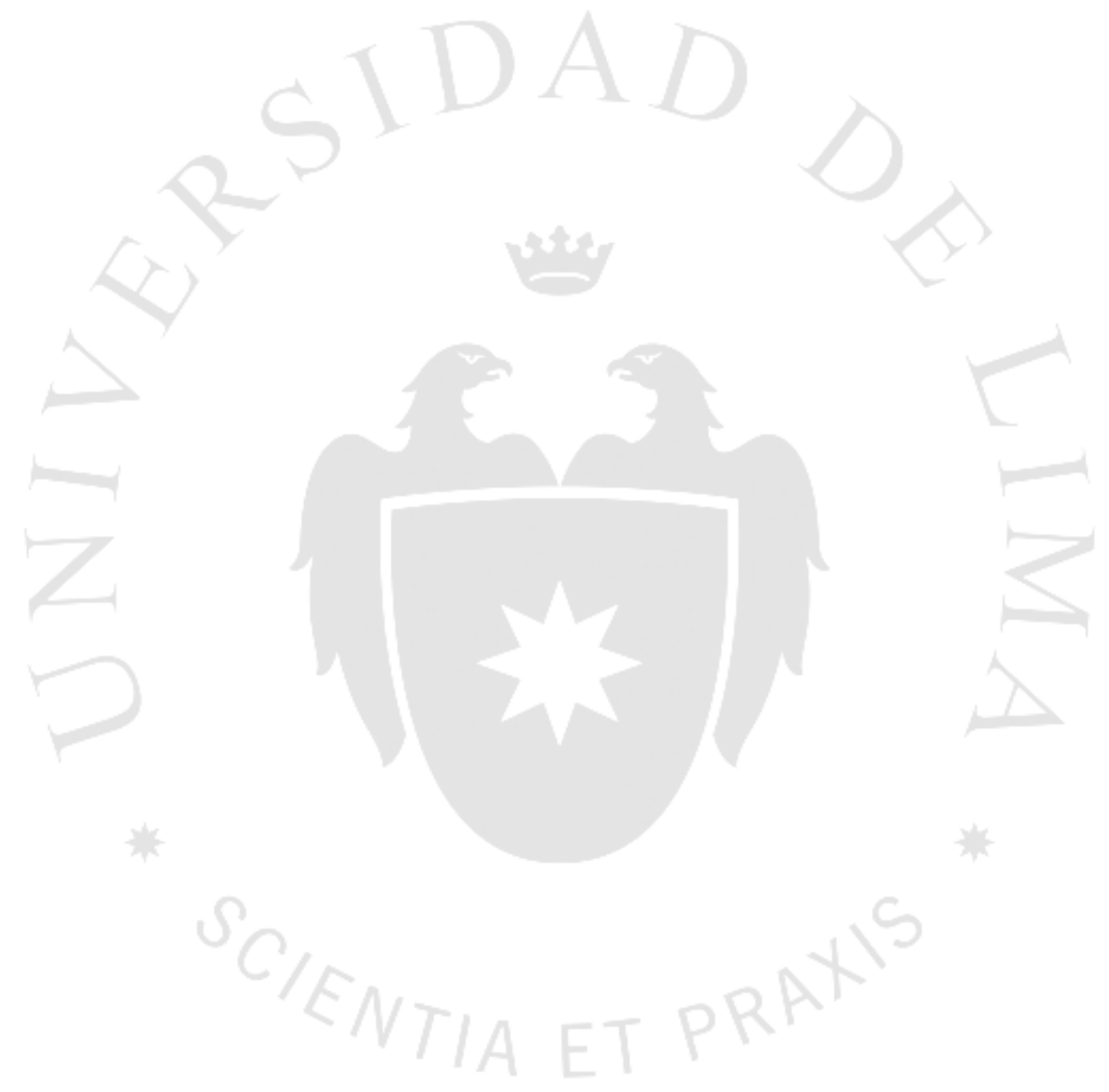




\section{LA DOBLE NO IMPOSICIÓN EN}

APLICACIÓN DE LOS CONVENIOS PARA EVITAR LA DOBLE IMPOSICIÓN 


\section{TABLA DE CONTENIDO}

INTRODUCCIÓN 1

CAPÍTULO I: ASPECTOS GENERALES SOBRE LA TRIBUTACIÓN DE LAS OPERACIONES INTERNACIONALES EN EL PERÚ ......................................... 3

1.1 Base jurisdiccional del Impuesto a la Renta ........................................... 3

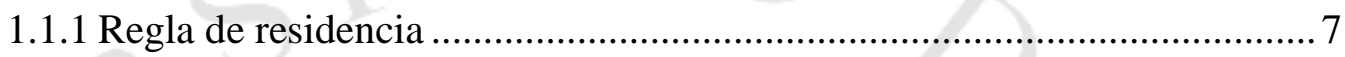

1.2.1 Regla de la fuente .......................................................................... 7

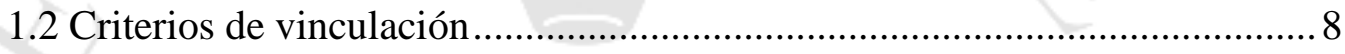

1.2.1 Criterio objetivo: renta de fuente peruana .......................................... 10

1.2.2 Criterio subjetivo: reglas para la determinación del domicilio................. 12

1.3 Actividades realizadas parte en el país y parte en el extranjero .................. 13

1.4 Métodos para eliminar la doble imposición ............................................ 14

CAPÍTULO II: LOS CONVENIOS PARA EVITAR LA DOBLE IMPOSICIÓN 18

2.1 Importancia, noción y clases de tratados internacionales ........................... 18

2.2 Consideraciones generales sobre los convenios para evitar la doble

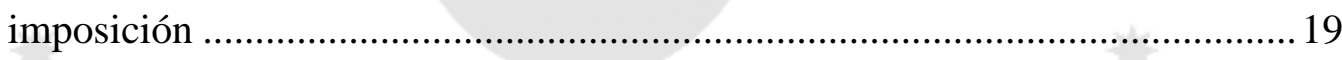

2.2.1 Definición de doble imposición .......................................................... 19

2.2.2 Doble imposición internacional jurídica y económica ........................... 19

2.2.3 Ventajas en la firma de convenios ..................................................20

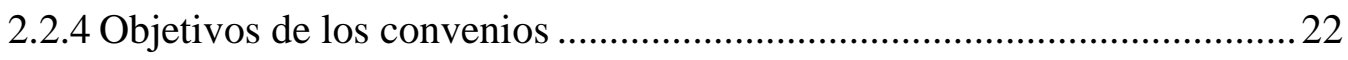

2.3 La interpretación de los convenios para evitar la doble imposición............22

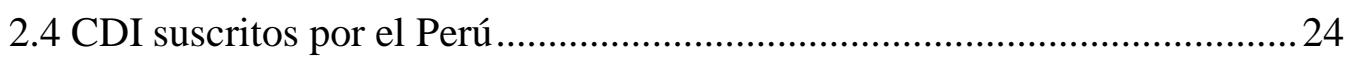

2.5 Decisión 578 de la Comunidad Andina ......................................................22

CAPÍTULO III: LA DOBLE NO IMPOSICIÓN EN LA APLICACIÓN DE LOS

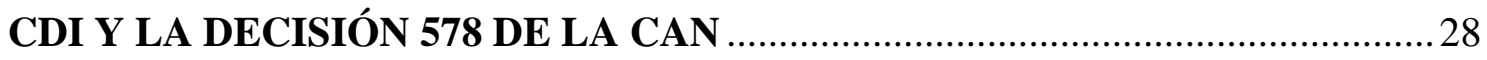


3.1 Definición de doble no imposición............................................................28

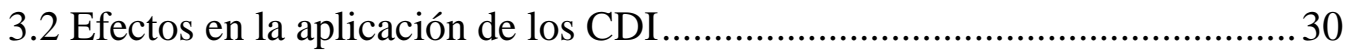

3.2.1 Doble no imposición en aplicación de los CDI firmados en el marco del

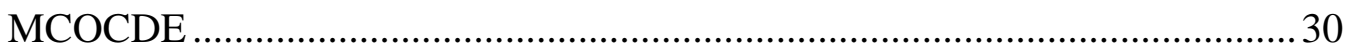

3.2.2 Doble no imposición en el marco de la Decisión 578 de la CAN ............. 35

3.3 El proyecto BEPS y su aplicación a supuestos de doble no imposición ......37

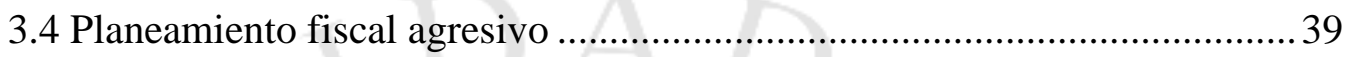

3.5 Casuística relacionada a operaciones de doble no imposición .................... 43

3.6 Propuestas para evitar la doble no imposición en la aplicación de los convenios

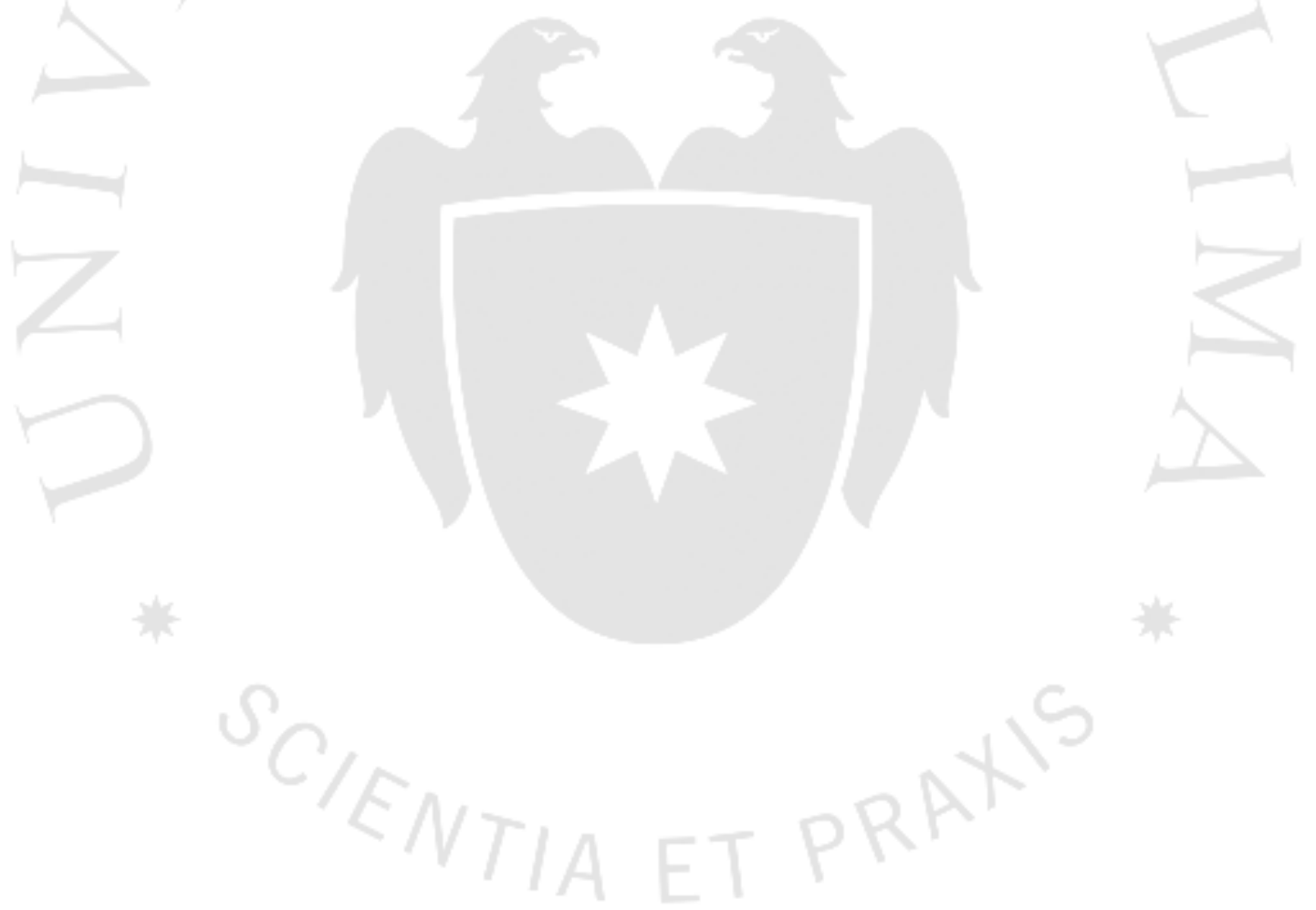




\section{INTRODUCCIÓN}

En los últimos años, las economías de los Estados han experimentado una creciente internacionalización, lo que ha producido un mayor movimiento de capitales, de bienes y de servicios.

En el caso de las personas naturales o jurídicas que obtienen renta en más de un país, estas podrían tributar en más de un Estado, originándose de esta manera una doble o múltiple imposición. Este fenómeno se produce cuando dos o más Estados ejercen su potestad tributaria sobre un mismo hecho imponible, por lo que ha sido necesario establecer mecanismos para evitar un gravamen excesivo sobre los contribuyentes.

Uno de estos mecanismos es la suscripción de convenios para evitar la doble imposición entre dos o más Estados, y son diseñados teniendo como base algunos modelos propuestos, por ejemplo, el modelo de la ONU o la OCDE.

Si bien los CDI suscritos por los Estados tienen como objetivo solucionar el problema de la doble imposición internacional, su aplicación ha revelado efectos inesperados. Pensemos, por ejemplo, en ciertas situaciones que deberían estar sujetas al Impuesto a la Renta y terminan no tributando en ninguna jurisdicción; esto es lo que se conoce como "doble no imposición".

La doble no imposición ocurre frecuentemente cuando el Estado que debe gravar una renta, conforme a las cláusulas de un CDI, no lo hace porque su legislación interna la exonera o inafecta, mientras que el otro Estado contratante no puede gravarla tampoco en virtud al propio convenio, quedando así esa ganancia sin tributar en ningún país.

Lo comentado en las líneas precedentes ha motivado el estudio de este fenómeno a fin de encontrar y sugerir posibles mecanismos que eviten que, a propósito de la aplicación de un CDI, una determinada ganancia no resulte gravada por ninguno de los Estados contratantes.

Para desarrollar este tema de investigación hemos estructurado los puntos a tratar en tres capítulos. El primero de ellos aborda los aspectos fundamentales de la tributación de las rentas derivadas en las operaciones internacionales. 
Luego, en el segundo capítulo analizaremos conceptos básicos, tales como la importancia, noción y clases de tratados internacionales, así como consideraciones generales sobre los CDI, además de los convenios vigentes en nuestro país, así como la Decisión 578 de la Comunidad Andina, suscrita por Perú, Colombia, Ecuador y Bolivia.

Finalmente, en el tercer capítulo estudiamos el problema de la doble no imposición en el marco de la aplicación de los CDI, identificando algunas situaciones en las que ocurre este fenómeno y planteando propuestas que podrían implementarse a fin de evitar una distorsión al momento de aplicar un acuerdo entre los Estados que busca evitar la doble imposición, mas no la doble no imposición. 


\section{CAPÍTULO I: ASPECTOS GENERALES SOBRE LA TRIBUTACIÓN DE LAS OPERACIONES INTERNACIONALES EN EL PERÚ}

En nuestro país, de acuerdo a lo señalado por el artículo $6^{\circ}$ del Texto Único Ordenado de la Ley del Impuesto a la Renta, todos los sujetos domiciliados deben tributar por las rentas de fuente peruana y las rentas de fuente extranjera que perciban; mientras que los sujetos no domiciliados solo tributan por las rentas de fuente peruana que obtengan.

En el presente capítulo señalaremos los aspectos fundamentales de la tributación de las rentas derivadas de operaciones internacionales que realiza el Perú, hablaremos sobre la base jurisdiccional del Impuesto a la Renta, los criterios de conexión, además se desarrollarán algunas actividades que se realizan parte en el país y parte en el extranjero $\mathrm{y}$, finalmente, describiremos los métodos que existen en la doctrina para eliminar la doble imposición.

\subsection{Base jurisdiccional del Impuesto a la Renta}

Cuando señalamos la base jurisdiccional en el Impuesto a la Renta nos referimos a aquellos nexos o puntos de conexión para que un Estado delimite su campo jurisdiccional; es decir, los supuestos que determinan el nacimiento de la obligación de tributar dentro de un determinado territorio. Entonces, diremos que no es suficiente que exista un concepto de renta para encontrarse gravado con el Impuesto a la Renta, sino que es fundamental que en la ley exista algún nexo o vinculación entre el acreedor (Estado) y el sujeto obligado al pago del impuesto (Escobar, Neyra y Vásquez, 2012 p.9).

Para que el hecho imponible irradie efectos tributarios contenidos en las normas que cada soberanía cuenta en su legislación producto de su poder tributario, debe existir algún punto de conexión entre el sujeto pasivo y el acreedor tributario, caso contrario no existiría obligación de afectarlo al Impuesto a la Renta, lo que en doctrina se denomina criterios de vinculación o principios de imposición jurisdiccional.

Los Estados tienen la potestad de dividir el universo de sus contribuyentes entre quienes residen en su territorio y quienes no; y determinar, en consecuencia, conforme a 
su exclusiva decisión de política tributaria, la forma de imposición de los distintos tipos de renta obtenidos dentro y fuera de su territorio. (Tillinghast, 1984, p. 239)

Uckmar (2003) sostiene lo siguiente:

La comunidad internacional está formada por Estados soberanos dotados de potestad normativa primaria e independiente. Cada Estado puede imponer su propia potestad tributaria a todas aquellas circunstancias que impliquen una relación económica con su propio sistema estatal, aun en los casos en que el mismo hecho imponible se encuentre vinculado por algún elemento a otros ordenamientos jurídicos. Cada Estado puede imponer tributos a cualquiera que se encuentre en el ámbito de su propia potestad de imperio, de la cual la tributaria no es más que una de sus manifestaciones, lo que puede dar lugar a un conflicto de jurisdicciones en razón de la falta de límites del poder impositivo de cada Estado, derivados de la ley interna o del derecho público internacional, respecto de hechos vinculados a su propio territorio. (p.86)

Por otro lado Morris Guerinnoni (2006) señala:

Las leyes de carácter tributario establecen puntos de conexión o vínculos en orden a señalar los supuestos que determinan el nacimiento de los hechos imponibles $\mathrm{y}$, consecuentemente, la obligación de tributar dentro de un territorio. Pueden gravarse hechos ocurridos en el propio territorio o fuera del mismo, así como comprender a sujetos nacionales o extranjeros. Los puntos de conexión atienden a diferentes criterios que son elegidos unilateralmente por cada Estado en el ejercicio de su potestad tributaria, siempre respetando los principios tributarios. (p .985)

Ahora bien, los Estados no aplican en forma exclusiva un único punto de conexión al delimitar su base jurisdiccional, sino que en las leyes sobre Impuesto a la Renta destacan principalmente los vínculos del domicilio o residencia, y el lugar de obtención de la renta. (Escobar et al., 2012).

Como sostiene García Mullín (1980):

Para que un enriquecimiento calificado abstractamente como renta para una legislación genere el impuesto correspondiente, no basta con que encaje en la descripción hipotética de la ley, sino que además es necesario que tenga algún tipo de conexión o vinculación con el país; que por alguna circunstancia, el Estado se atribuya jurisdicción, en el sentido de potestad tributaria, para hacer tributar ese fenómeno a sus arcas. (p. 35)

Cada Estado tiene el poder de legislar de acuerdo a lo que considere más conveniente a sus intereses, a efectos de que pueda cumplir con el objetivo de lograr el bien común de la sociedad, enfocado a satisfacer las necesidades públicas de un país. 
Del mismo modo, como señala Braccia (2016): "Los Estados conservan la soberanía tributaria para adoptar los diferentes regímenes y opciones disponibles sin intromisión alguna de los demás Estados u organizaciones internacionales, reservándose el derecho de efectuar concesiones a nivel convencional” (p. 4)

En ese sentido, García Mullin (1980), citando a Jarach, nos dice:

El poder fiscal no se halla limitado por principios superiores de orden jurídico, de derecho internacional ni constitucional ni tampoco por principios éticos, sino que, sustancialmente, el Estado adopta los criterios de imposición para determinar el ámbito de aplicación de los impuestos; criterios fundados en su interés político económico, sin perjuicio de los ideales de justicia en que debe inspirarse siempre la actividad legislativa. (p. 35)

Este autor y otros que están en la misma línea, entienden que los Estados poseen plena libertad para señalar el criterio que más convenga a sus intereses.

Compartimos la misma posición señalada por diversos autores; sin embargo, existen límites que deben ser cumplidos a efectos de no violar el principio de capacidad contributiva a la que tiene derecho todo ciudadano que forma parte del Estado.

Si bien en la doctrina encontramos el principio del deber de contribuir, en nuestra Constitución no se encuentra explícitamente consignado; sin embargo, de alguna manera el Tribunal Constitucional se ha referido al principio de capacidad contributiva de forma indirecta, en el sentido de que la capacidad contributiva guarda un nexo indisoluble con el hecho sometido a imposición (STC N 1907-2003-AA/TC).

Como señala Bravo Cucci (2006): "El principio de capacidad contributiva es un límite a la potestad normativa que ejerce el Estado en materia tributaria, no siendo una mera directriz o recomendación al legislador, sino un mandato preceptivo y vinculante" (p. 105).

Los criterios de conexión o vinculación pueden ser subjetivos u objetivos. Entre los subjetivos tenemos a los de residencia, domicilio y nacionalidad, que tienen como punto de conexión atributos o características personales de los contribuyentes; mientras que entre los objetivos destaca el de la fuente, vale decir, el lugar en donde se genera la renta.

En ese sentido, Reig (2006) señala lo siguiente: 
(...) En derecho tributario a los criterios para vincular la sustancia gravable con el Estado que ejercerá dicha potestad, se los conoce con el nombre de momentos de vinculación y, a dicho vínculo, como vínculo jurisdiccional.

Las legislaciones se orientan de diversas maneras al escoger tal momento, y así los criterios utilizados resultan ser: el del domicilio, residencia o nacionalidad del beneficiario de la renta, llamado también principio de la universalidad o de la renta mundial o global, y el de ubicación territorial o geográfica de la fuente de donde proviene, o principio del país de origen, desechando en general el lugar de celebración de los contratos. (p. 91)

En el Perú, de acuerdo a lo señalado en la Ley del Impuesto a la Renta (en adelante, Ley de Renta) $)^{1}$, en el artículo $6^{\circ}$ se observa que para determinar la base jurisdiccional del impuesto se recogen como puntos de conexión los criterios del domicilio y la fuente de la renta, tal como se muestra a continuación:

Están sujetas al impuesto la totalidad de las rentas gravadas que obtengan los contribuyentes que, conforme a las disposiciones de esta Ley, se consideran domiciliados en el país, sin tener en cuenta la nacionalidad de las personas naturales, el lugar de constitución de las jurídicas, ni la ubicación de la fuente productora.

Esto implica que cuando un sujeto tenga la condición de domiciliado en el país, ya sea persona natural o jurídica, entre otros casos, deberá tributar renta por la totalidad de las rentas que obtenga dicho contribuyente, es decir, por la obtención de rentas de fuente peruana y rentas de fuente extranjera. Cabe señalar que para ser consideradas domiciliadas en el país no se tiene en cuenta la nacionalidad de las personas naturales, el lugar de constitución de las jurídicas ni la ubicación de la fuente productora.

Sin embargo, en el segundo párrafo del artículo $6^{\circ}$ de la Ley de Renta se precisa que tratándose de contribuyentes no domiciliados en el país, de sus sucursales, agencias o establecimientos permanentes, el impuesto recae solo sobre las rentas gravadas de fuente peruana.

Esto implica que en caso de que los sujetos no domiciliados se encuentren obligados a tributar con el Impuesto a la Renta en el Perú, no solo basta que la renta se encuentre dentro de los supuestos y conceptos de domicilio, sino que además debe estar

\footnotetext{
1 Texto Único Ordenado (TUO) aprobado por el Decreto Supremo $\mathrm{N}^{\circ}$ 179-2004-EF y normas modificatorias.
} 
definida como renta de fuente peruana de acuerdo a la legislación que señala este tipo de rentas.

En tal sentido, si el servicio es prestado por un sujeto no domiciliado a favor de algún contribuyente domiciliado en el Perú, solo se considerará gravada con el Impuesto a la Renta la retribución que el sujeto no domiciliado perciba en el Perú y no la renta que perciba en otras partes del mundo, figura que recoge nuestra legislación nacional.

Por lo general, las leyes internas de los países aplican el siguiente principio internacional basado en factores conectores como son la regla de residencia y la regla de la fuente.

\subsubsection{Regla de residencia}

Derechos ilimitados para cobrar impuestos que son otorgados al país de residencia, con base en la "conexión personal" de las personas. El país de residencia (o nacionalidad) puede imponer sus impuestos sobre los ingresos mundiales de individuos o corporaciones debido a la protección que le ofrece al sujeto de impuestos (Escobar et al., 2012).

El criterio de residencia supone que un residente de un Estado determinado, con independencia de la localización de la fuente de la renta, tributará en su país de residencia por toda la renta de fuente mundial (rendimientos obtenidos en cualquier parte del mundo). Este criterio se basa en el trato igualitario de todos los sujetos a la imposición, pues no es justo discriminar en la imposición entre quienes obtienen renta dentro del país y aquellos que la obtienen en el exterior, así como mide en mayor grado la capacidad contributiva, pues a través de esta imposición global se mide la capacidad de contribuir con las cargas públicas del Estado donde el sujeto reside. (Zuzunaga, 1984, pp.5-6)

En esta regla podemos citar como ejemplo los ingresos que percibe un residente peruano tanto en el país como en el extranjero; aquellos ingresos percibidos de fuente mundial estarán sujetos a gravamen, por ser aquel un ciudadano residente en el Perú.

\subsubsection{Regla de la fuente}

Derechos ilimitados para cobrar impuestos que son otorgados al país de la fuente con base en la "conexión económica" de las personas. El país de la fuente se reserva el 
derecho a gravar los ingresos que se derivan de las actividades económicas dentro de su territorio. (Escobar et al., 2012).

Este criterio de la fuente otorga el poder de gravar al Estado donde se produce o realiza la renta, independientemente de donde el sujeto afecto al Impuesto a la Renta resida.

A mayor abundamiento, Sol Gil (2006) señala:

Que generalmente este criterio es recogido por los países importadores de capitales o jurisdicciones cuya administración tributaria tiene un desarrollo precario o por los llamados paraísos fiscales. Quienes justifican desde el punto de vista de la teoría tributaria y económica este criterio se basa en que la renta y el patrimonio han de ser gravados en el Estado donde se producen o detentan, lo cual atiende al principio de neutralidad en la importación de capitales, esto es, con independencia de la procedencia del capital, este estará gravado en forma igual en el territorio donde se origina sin discriminación. (p. 74)

En esta segunda regla podemos señalar como ejemplo los ingresos de un ciudadano chileno que presta servicios en el Perú, aquel ingreso estará sujeto a gravamen en el Perú en la medida en que sus ingresos se desarrollen en territorio peruano.

\subsection{Criterios de vinculación}

Los criterios de vinculación se refieren a la existencia de determinados nexos o vínculos entre el sujeto pasivo del impuesto y el Estado a efectos de que este último, en su calidad de acreedor tributario, pueda ejercer su potestad tributaria para exigir el pago de los impuestos.

A nivel doctrinario existen varios criterios de vinculación, los más conocidos son básicamente tres:

- Domicilio: entendido como el lugar donde vive o desarrolla la mayor parte de sus actividades una persona natural o el lugar de constitución de una persona jurídica.

- Nacional: vínculo político y social que une a una persona ("nacional”) con el Estado al que pertenece. Actualmente, este criterio solo lo utilizan Estados Unidos y Filipinas. 
- Fuente: criterio más utilizado donde se prioriza el lugar donde se está generando o produciendo la renta (Escobar et al., 2012).

Para algunos autores, como Gildemeist (2000), existen solo dos criterios de vinculación, que son los siguientes:

a) El criterio de la residencia: la obligación personal de someter a gravamen las rentas que perciban y el patrimonio que posean los residentes en territorio nacional, cualquiera que sea el lugar de origen de dichas rentas o donde esté situado el patrimonio. En otras palabras, en virtud de este criterio, se somete a gravamen las rentas de fuente mundial de un residente, es decir, tanto las que provengan del extranjero como las que se produzcan en el propio suelo nacional. En cambio, si se es no residente, se someterán a gravamen tan solo las rentas que se perciban de territorio nacional y el patrimonio que se posea en el mismo.

b) El criterio de territorialidad: solo se gravarán los hechos imponibles que tengan lugar en territorio peruano. La ley creadora de cada tributo en particular deberá precisar los casos en los cuales se considere que un hecho imponible determinado se ha realizado en territorio peruano. El criterio de la territorialidad abarcará la totalidad de los no residentes y aparte de los residentes. Esto último debido a que existirán rentas de residentes cuyo origen no sea el territorio peruano.

Por lo tanto, podemos afirmar que el Estado, en virtud de su poder de imposición o poder imponible, puede ejercer dicho poder dentro de su territorio y gravar a las personas ya sean estas residentes, nacionales como extranjeros, o no residentes en razón de los hechos imponibles producidos dentro de los límites de su territorio.

Un Estado tiene poder para gravar los hechos imponibles ocurridos en otro Estado siempre y cuando exista algún criterio de conexión con el primer Estado, tal como el de residencia, territorialidad e inclusive el de la nacionalidad. Además, un Estado, en virtud de su poder impositivo, puede gravar los hechos imponibles ocurridos en su territorio aunque el sujeto pasivo sea residente en el extranjero. (pp. 32-35)

Por su parte, Morris Guerinnoni (2006) respecto a los criterios de vinculación, señala que también existen dos criterios como puntos de conexión, que son los siguientes:

a) El domicilio: bajo este criterio, la persona puede estar sujeta a imposición en consideración a su domicilio efectivo. El Estado podrá someterlo a tributación en caso de que reúna las condiciones establecidas en la legislación fiscal para ser considerado residente o domiciliado. Si se pretende gravar la capacidad económica del sujeto, la 
norma tributaria dispondrá que los residentes estén gravados por todas sus rentas, con independencia del lugar de obtención de las mismas (fuente mundial).

Las legislaciones tributarias definen la residencia de la persona natural en función de diferentes situaciones como la de presencia física en el territorio del Estado durante un determinado periodo, relaciones familiares, económicas y sociales en dicho país, así como otras circunstancias que demuestren la intención del sujeto de permanecer en forma prolongada -no temporal- en un determinado lugar.

En el caso de las personas jurídicas, se establecen distintos criterios para determinar su lugar de residencia como son el país en que fue constituida o registrada la sociedad, el lugar de residencia de sus accionistas o administradores, el lugar en donde se encuentra la dirección efectiva de la sociedad o el lugar en donde realiza su mayor producción y/o desarrolla sus principales actividades.

Fuente de la renta: el concepto de fuente se relaciona, en líneas generales, con el territorio de procedencia de la renta; el lugar de producción o generación de los beneficios. Los Estados se atribuyen el poder de gravar los hechos imponibles que se originan o que producen efectos dentro de su territorio, con prescindencia de la nacionalidad o domicilio de los sujetos que intervienen o el lugar de celebración o cumplimiento del contrato. (pp. 988-993)

Según Serrano Antón (2004), quien recoge la posición de A. Xavier:

(...) se puede aceptar la clasificación de los puntos de conexión entre personales y territoriales, siendo un punto de conexión personal, la nacionalidad; y constituyendo puntos de conexión territoriales, a su vez de dos tipos, los subjetivos y los objetivos; en cuanto al punto de conexión territorial subjetivo, tenemos que citar la residencia, como vínculo entre el contribuyente y el territorio; mientras que el punto de conexión territorial objetivo, se determina a través de la conexión entre territorio y el acto o situación sobre la que se estructura el hecho imponible. (p. 10)

\subsubsection{Criterio objetivo: renta de fuente peruana}

Bajo este supuesto se encuentra inmerso el criterio de la fuente, que es aquel que comprende el lugar de obtención de la renta, la manifestación de riqueza, la realización del servicio, el uso del mercado, la utilización económica, entre otros. Es decir, que el Estado para cobrar tributo no tendrá en consideración la nacionalidad, ciudadanía, 
domicilio o residencia del sujeto pasivo (no domiciliado), sino la fuente de donde proviene la renta.

En ese sentido, se considera que el país donde se ubica el bien o actividad que genera la renta será aquel legitimado para realizar el cobro del tributo, en virtud de que el mismo fluye de una fuente correspondiente al circuito económico del Estado; es por ello que todo ingreso que proviene del extranjero será considerado como renta de fuente extranjera, a pesar de que sea percibido por sujetos domiciliados o por nacionales (Escobar et al., 2012).

En la legislación peruana, este criterio se utiliza en los artículos $9^{\circ}, 10^{\circ}$ y $11^{\circ}$ de la Ley del Impuesto a la Renta, a efectos de cobrarles impuesto a los no domiciliados por los beneficios que obtienen por actividades que están vinculadas con el territorio peruano, siendo estos los siguientes:

a) Lugar de situación: este criterio se relaciona con el lugar en donde se encuentra localizada físicamente la fuente productora. Es así que se consideran rentas de fuente nacional los beneficios producidos por bienes muebles e inmuebles y los derechos sobre ellos situados dentro del territorio peruano, incluyendo los que provienen de su enajenación. Este criterio se encuentra recogido en los incisos a) y b) del artículo $9^{\circ}$ de la Ley de Renta.

b) Lugar de colocación: este criterio se utiliza para definir el lugar de fuente de los beneficios generados por préstamos y créditos. Es decir, que al colocar un capital (préstamo) se tiene como lugar de realización de esta operación el domicilio del deudor. Este criterio se encuentra en el inciso c) del artículo $9^{\circ}$ de la Ley de Renta.

c) Lugar de realización: este criterio depende del lugar en donde se ejecuta o se desarrolla un determinado trabajo o servicio. Así, tenemos que este criterio se encuentra contenido en los incisos e) y f) del artículo $9^{\circ}$ de la Ley de Renta.

d) Lugar de utilización económica: este criterio se relaciona con el lugar en donde el servicio se utilice económicamente, es decir, donde ocurre el aprovechamiento económico. Este criterio se encuentra contenido en los incisos b), c), i) y j) del artículo $9^{\circ}$ de la Ley de Renta. 
e) Lugar de residencia de la entidad emisora: este criterio se encuentra en función del lugar de domicilio de la entidad que emite los valores mobiliarios. Este criterio está contenido en el inciso d) del artículo $9^{\circ}$ de la Ley de Renta.

f) Lugar de residencia del pagador: de acuerdo a este criterio, están sujetas al tributo las rentas de los no domiciliados cuando son pagadas por un domiciliado en el país. Así, tenemos que el inciso g) del artículo $9^{\circ}$ de la Ley de Renta recoge este criterio.

\subsubsection{Criterio subjetivo: reglas para la determinación del domicilio}

En este criterio se encuentran comprendidos la nacionalidad y la residencia o domicilio; es decir, que toma en consideración circunstancias relacionadas con el sujeto pasivo o el estatus personal de las personas que realizan el hecho económico, por lo que se detalla cada uno de ellos:

a) Nacionalidad: lo importante para este criterio es la nacionalidad del sujeto pasivo (no domiciliado), esto significa que las rentas que perciben las personas serán gravadas en el país del cual son nacionales. Este criterio es utilizado únicamente para personas naturales.

b) Residencia: según este criterio, la persona puede estar sujeta a renta en función de su domicilio efectivo; es decir, que el Estado podrá someterlo a tributación en caso de que reúna las condiciones establecidas en la legislación fiscal para ser considerado residente o domiciliado. Cabe señalar que el domicilio es el lugar donde el contribuyente reside habitualmente y tiene sustento social, toda vez que se fundamenta en que aquel que vive en determinada forma organizada de sociedad debe contribuir a su financiamiento. Este criterio se aplica tanto a personas naturales como a jurídicas (Escobar et al., 2012).

Morris Guerinnoni (2006) señala lo siguiente:

Las legislaciones tributarias definen la residencia de la persona natural en función de diferentes situaciones como la de presencia física en el territorio del Estado durante un determinado periodo, relaciones familiares, económicas y sociales en dicho país, así como otras circunstancias que demuestren la intención del sujeto de permanecer en forma prolongada -no temporal- en un determinado lugar. 
En el caso de personas jurídicas, se establecen distintos criterios para determinar su lugar de residencia como son: el país en que fue constituida o registrada la sociedad, el lugar de residencia de sus accionistas o administradores, el lugar en donde se encuentra la dirección efectiva de la sociedad, o el lugar en donde realiza su mayor producción y/o desarrolla sus principales actividades. (pp. 988-989)

De acuerdo a lo señalado en los párrafos precedentes y a manera de resumen, los criterios de vinculación son los siguientes:

\section{Criterio subjetivo:}

Persona natural:

- Nacionalidad

- Ciudadanía

- Residencia

- Domicilio

Persona jurídica:

- Lugar de constitución

- Sede de dirección

- Sede de control

\section{Criterio objetivo:}

- Ubicación de la fuente:

- Ubicación física

- Utilización económica

- Pagador

\subsection{Actividades realizadas parte en el país y parte en el extranjero}

Con respecto a la renta de fuente peruana, en el artículo $12^{\circ}$ de la Ley de Renta se hace referencia a rentas por actividades que se realizan parte en el país y parte en el extranjero, las cuales podrían considerarse como actividades internacionales.

En este caso aplican presunciones absolutas a efectos de determinar las rentas obtenidas (base para aplicar el porcentaje del $30 \%$ ) por contribuyentes no domiciliados en el país, en la medida que realicen actividades que se llevan a cabo parte en el país y parte en el extranjero, señalando que son iguales a los importes que resulten de aplicar 
sobre los ingresos brutos provenientes de las mismas, los porcentajes que establece el artículo $48^{\circ}$ de la Ley de Renta (Escobar et al., 2012).

Se consideran incluidos en estas actividades las operaciones de seguros, reaseguros y retrocesiones; el alquiler de naves y aeronaves; el transporte y servicios de telecomunicaciones entre la República y el extranjero; el suministro de noticias por parte de agencias internacionales; el arriendo u otra forma de explotación de películas, cintas magnetofónicas, matrices u otros elementos destinados a cualquier medio de proyección o reproducción de imágenes o sonidos; y la provisión y sobrestadía de contenedores para el transporte en el país (Escobar et al., 2012).

En caso dichas actividades sean desarrolladas por contribuyentes domiciliados en el país, se presume de pleno derecho que la renta obtenida es íntegramente de fuente peruana, excepto en el caso de sucursales, agencias o cualquier otro establecimiento permanente en el país de empresas unipersonales, sociedades y entidades de cualquier naturaleza constituidas en el exterior, cuyas rentas se determinarán según el procedimiento establecido en el artículo $12^{\circ}$ de la Ley de Renta. (Escobar et al., 2012).

En ese sentido, si un no domiciliado presta servicios de transporte marítimo desde su país hacia el Perú, aquel servicio se está prestando tanto en territorio peruano como en el extranjero, situación que conlleva aplicar el artículo $48^{\circ}$ de la Ley de Renta a efectos de determinar el correspondiente pago de renta por la parte de los servicios prestados en el Perú.

\subsection{Métodos para eliminar la doble imposición}

Calderón Carrero (1997) sostiene:

Que los métodos para evitar la doble imposición "están concebidos no tanto para suprimir o evitar su surgimiento como para reparar sus perjudiciales consecuencias. En efecto, (...) tanto el método de exención como el de imputación no erradican en origen la yuxtaposición de soberanías fiscales sobre el mismo hecho imposible, sino que están concebidos para aplicarse en la mayoría de las ocasiones, una vez que esta se ha producido corrigiendo sus efectos sobre el contribuyente que la soporta. (pp. 136-137) 
Las medidas que utilizan los Estados para evitar la doble imposición pueden ser tanto unilaterales, bilaterales o multilaterales, según se incorporen a través de las legislaciones nacionales o bien por medio de negociación y aceptación por las partes en el $\mathrm{CDI}^{2}$.

Ahora bien, cuando una misma renta está sujeta a impuestos por dos o más países, se afecta el principio de capacidad contributiva, situación que conlleva al uso de algún tipo de planeamiento o estrategia tributaria con la finalidad de disminuir o anular la carga tributaria, originando en mucho casos que esta figura contribuya a la evasión o elusión fiscal; en ese sentido, los Estados deben buscar soluciones a este tipo de problemas.

Para atenuar el efecto comentado en el párrafo anterior es que existen mecanismos descritos en los artículos $23^{\circ}$-A y $23^{\circ}$-B del capítulo V del Modelo $\mathrm{OCDE}^{3}$, el cual contiene los métodos para eliminar la doble imposición, el método de exención y el método de imputación o de crédito fiscal, respectivamente.

García Mullin (1978) señala:

Deben diferenciarse las "medidas" para evitar la doble imposición de los "métodos" para hacerlo: "El primer concepto dice relación con las características del instrumento normativo con el que ha de intentarse prevenir la doble imposición, en tanto el segundo se refiere a las características técnicas y operativas del sistema que se pone en práctica”. El mismo autor señala que las medidas para evitar la doble imposición pueden clasificarse en unilaterales (exención en el país de la fuente o crédito en el país de la residencia), bilaterales (CDI) o multilaterales (directivas de la Unión Europea o el caso de la Decisión 578 de la Comunidad Andina). (p. 202)

En lo que respecta a los métodos para eliminar la doble imposición, estos pueden operar sobre la base imponible (método de exención al gravamen sobre las rentas de fuente extranjera o de prorrateo de rentas) o sobre el impuesto a pagar (siendo el más común el del crédito por impuesto pagado, conocido también como método de imputación), y pueden ser adoptados indistintamente por la legislación doméstica o a nivel de tratados bilaterales o multilaterales. (Córdova, 2008, p.13)

Por otro lado Calderón, Carmona, Jimenez y Trapé (2005) señala lo siguiente:

Los CDI integran un auténtico sistema de coordinación de poderes tributarios y de principios jurídicos sobre una base de consenso y reciprocidad cuyo principal objetivo reside en eliminar la doble imposición internacional que se produce por el solapamiento

\footnotetext{
${ }^{2}$ Convenio para evitar la Doble Imposición

${ }^{3}$ Organización para la Cooperación y el Desarrollo Económicos
} 
de los impuestos de los Estados contratantes sobre el mismo hecho imponible y sujeto pasivo. Precisamente, la coordinación de poderes tributarios que estos convenios articulan es lo que permite establecer a través de los mismos un sistema de eliminación de la doble imposición cualitativamente distinto y más acabado que el instrumentado a través de medidas unilaterales. (p. 387)

\section{- Método de exención:}

Rubio Guerrero (2002) ha manifestado que, conforme al método de la exención: La renta se grava exclusivamente en uno de los países considerados, quedando exenta en los restantes. La exención supone la renuncia por parte de un Estado a la percepción de su impuesto cuando este recae sobre contribuyentes que mantienen determinados lazos con otros Estados. (p. 68)

Este método contiene dos modalidades:

a) Exención íntegra: un Estado (generalmente el de residencia), al exigir el impuesto de sus residentes, excluirá del gravamen a todos sus efectos, aquellas rentas cuya imposición se reserva en exclusiva al otro Estado.

b) Exención con progresividad: según Eduardo Sotelo, bajo este modelo, si bien las rentas del exterior no son tomadas en cuenta para la determinación de la base imponible; sin embargo, sí son consideradas para la determinación de la alícuota aplicable (aumenta la base imponible) del sujeto residente respecto de sus demás rentas. (Sotelo, 1999, p.144)

En la misma línea, Bassallo Ramos (2008) señala que estamos frente al método de exención con progresividad cuando por aplicación del CDI resulte que una renta está exenta de gravamen en el país; esta podrá considerarse a efectos de calcular el importe del impuesto (tasa) sobre las demás rentas. (p. 396)

Sin embargo, el método de exención puede dar lugar a problemas de "doble no imposición internacional" si es que en el Estado de la fuente se otorga exoneraciones a las rentas susceptibles de gravamen, por lo que muchos países han optado por no utilizarlo, salvo en determinadas categorías de rentas o mediante la introducción que condiciona la exención a la efectiva imposición en el país de la fuente (subject to tax). (Córdova, 2008, p.15)

\section{- Método de imputación o de crédito fiscal:}


El país de residencia del inversor calcula el impuesto utilizando como base el importe total de las rentas percibidas, incluidas las procedentes del exterior, permitiéndose deducir de la cuota del impuesto en el país de la fuente. Este sistema es defendido principalmente por los países exportadores del capital.

Este método, al igual que el método anterior, contiene dos modalidades:

a) Crédito fiscal pleno o de imputación plena: bajo este método, el país de residencia permite deducir totalmente como crédito fiscal el impuesto pagado en el exterior (país de la fuente) sin limitación alguna. De este modo, el método permite que si el impuesto retenido en el país de la fuente excediera del importe del impuesto a pagar en el país de residencia, este último debería devolver el exceso al contribuyente. Lógicamente, esta exigencia de que el país de residencia del inversor tenga que asumir los impuestos extranjeros cuando el tipo de gravamen aplicado en el país de residencia resulte inferior al aplicado en el país de la fuente se convierte en un importante inconveniente que limita su viabilidad operativa.

b) Crédito fiscal con tope máximo o imputación limitada: bajo esta modalidad, el país de residencia permite deducir como crédito fiscal el impuesto pagado en el exterior, pero solo hasta el límite que suponga aplicar el tipo o tasa media de gravamen del Estado de la residencia sobre las rentas obtenidas en el exterior. (Zuzunaga, 2008, p.p 8-9)

Como señala Ault (1997):

Bajo el mecanismo del crédito por impuesto extranjero, la renta extranjera es incluida en la base del impuesto, admitiéndose el derecho del país de la fuente de gravarla al reconocer como crédito el impuesto pagado en el extranjero hasta el límite de la obligación doméstica que normalmente hubiera resultado aplicable. Si la tasa del impuesto en el país de la residencia es mayor que en el Estado de la fuente, un tributo adicional doméstico será recaudado, pero en el plano internacional la doble imposición se habría eliminado. Si la tasa extranjera fuera mayor que la doméstica, el total del impuesto local queda eliminada y, de nuevo, la doble imposición habría quedado anulada. (p. 15) 


\section{CAPÍTULO II: LOS CONVENIOS PARA EVITAR LA DOBLE IMPOSICIÓN}

En el presente capítulo trataremos la importancia, noción y clases de tratados internacionales, así como las consideraciones generales e interpretación de los convenios; finalmente, describiremos las cláusulas más resaltantes de los convenios suscritos y vigentes, así como la Decisión 578 de la Comunidad Andina, de la cual el Perú es país miembro, conjuntamente con Colombia, Ecuador y Bolivia.

\subsection{Importancia, noción y clases de tratados internacionales}

En el actual contexto de globalización económica no puede dejar de señalarse cómo los tratados internacionales cada vez ejercen una influencia más determinante a la hora de configurar el poder tributario de los Estados. Es así que Calderón, et al., (2005) los define estos conceptos de la siguiente manera:

Importancia: los tratados internacionales son hoy una fuente principal del Derecho Tributario; la importancia que poseen estos tratados se explica, en buena medida, considerando las diferentes implicaciones derivadas de los fenómenos de internacionalización y globalización económica acontecidos en las últimas décadas.

Los tratados internacionales constituyen una fuente del Derecho Tributario clásico o tradicional que se ha venido empleando para encauzar las relaciones entre los diferentes Estados integrantes de la comunidad internacional. A medida que estas relaciones y las de sus ciudadanos y empresas se han intensificado, los tratados han ido ampliando correlativamente su ámbito material y su número.

Noción: la noción clásica de tratado internacional la proporciona la Convención de Viena sobre el Derecho de los Tratados, la cual define el tratado internacional como "[u]n acuerdo internacional celebrado por escrito entre Estados y regido por el Derecho Internacional, ya conste en un instrumento único o en dos o más instrumentos conexos y cualquiera que sea su denominación particular". 
En este sentido, constituye un tratado internacional todo acuerdo escrito entre Estados celebrado con arreglo al Derecho Internacional, con independencia de su denominación como "acuerdo", "carta", "canje de notas", "protocolo", etc.

Los tratados internacionales que se encuentran en vigor despliegan importantes efectos para los Estados parte (y para las personas físicas y jurídicas comprendidas en su ámbito subjetivo de aplicación), en la medida en que, con carácter general, limitan o modifican el ejercicio de los poderes soberanos que corresponden a los Estados con arreglo al Derecho Internacional. Este principio o regla de pacta sunt servanda viene recogida en el artículo $26^{\circ}$ de la Convención de Viena sobre el Derecho de los Tratados.

Clases de tratados internacionales: el principal criterio de clasificación de los tratados internacionales atiende al número de partes contratantes. Así, cabe distinguir entre tratados bilaterales y multilaterales, dependiendo de si son dos o más de dos los sujetos que concluyen el pacto internacional. También se diferencia entre tratados internacionales generales y restringidos, dependiendo de si están abiertos a la firma de cualquier Estado o, por el contrario, solo afectan a un determinado grupo de países sin posibilidad de que otros se adhieran al mismo. En el ámbito estrictamente tributario, nos encontramos tanto con convenios bilaterales (los convenios de doble imposición) como con tratados multilaterales (Decisión 578 de la Comunidad Andina); también existen convenios generales que contienen cláusulas con relevancia jurídico-tributaria y tratados específicamente fiscales como los CDI. (pp. 27-28)

\subsection{Consideraciones generales sobre los convenios para evitar la doble imposición}

\subsubsection{Definición de doble imposición}

La doble o múltiple tributación se presenta cuando una misma ganancia puede resultar gravada por más de un Estado; es decir, que dos o más países consideran tener potestad para gravar una determinada renta que les pertenece. Ello ocasiona que se generen conflictos de jurisdicción, vale decir, que una misma ganancia es pretendida por el poder impositivo de más de un Estado.

\subsubsection{Doble imposición internacional jurídica y económica}


Doble imposición económica: Se presenta cuando un mismo ingreso o bien es gravado por dos o más países durante un mismo periodo, pero en cabeza de diferentes personas. De esta manera, en la doble imposición económica a nivel internacional existe identidad de objeto, periodo de tiempo y similitud de impuesto; sin embargo, se encuentra ausente el requisito de la identidad subjetiva, que sí es considerado por la doble imposición jurídica. (Zuzunaga, 2008, p.3)

Doble imposición jurídica: Esta consiste en que es la misma persona la que resulta gravada varias veces por el mismo concepto en el mismo periodo. Teodoro Ezquerro señala que la doble imposición jurídica se contempla como el resultado de la percepción de impuestos semejantes en dos o más países, de un mismo contribuyente, sobre la misma materia imponible y el mismo periodo de tiempo (Escobar et al., 2012).

De este modo, la importancia de la firma de convenios radica en que contemplan no solo las reglas que usarán para evitar la doble imposición, sino también los mecanismos de colaboración entre las administraciones tributarias a fin de detectar casos de evasión o elusión fiscal (Escobar et al., 2012).

En resumen, podríamos afirmar que mediante el uso de los convenios, los Estados partes renuncian a gravar determinadas ganancias y acuerdan una atribución de potestad tributaria compartida o, de lo contrario, que solo uno tenga la potestad tributaria exclusiva de gravar. La atribución compartida o exclusiva mencionada dependerá del criterio de vinculación que se adopte, por lo que si se adopta el criterio de territorialidad, o de la fuente u origen de la renta, fundamenta el derecho de gravamen de un país en la localización de fuentes de renta dentro de un territorio nacional. De otro lado, el criterio de sujeción de la residencia supone que un residente de un Estado determinado, con independencia de la localización de la fuente de la renta, va a tributar en su país de residencia por toda la renta mundial (rendimientos obtenidos en cualquier parte del mundo) (Escobar et al., 2012).

Este criterio se basa en el trato igualitario de todos los sujetos a la imposición, pues no es justo discriminar en la imposición entre quienes obtienen renta dentro del país y aquellos que la obtienen en el exterior. (Escobar et al., 2012).

\subsubsection{Ventajas en la firma de convenios}


Las ventajas de firmar convenios para evitar la doble imposición son múltiples, y según Escobar et al., (2012), así tenemos a las siguientes:

- Generan un ambiente favorable a la inversión, pues al firmar un convenio para evitar la doble tributación, un país está dando una señal positiva a la inversión extranjera y otorga a los inversionistas seguridad respecto de los elementos negociados, aun en el caso de modificación de la ley interna.

- Consolidan un marco legal, seguro y predecible, que resulta vital para la toma de decisiones de los inversionistas del país donde realicen sus inversiones, por estar salvaguardados por un convenio de carácter internacional, ofreciendo garantías contra la discriminación y la doble tributación.

- Son instrumentos que pueden usar además las administraciones tributarias para enfrentar la evasión fiscal internacional, ya que proveen acuerdos de intercambio de información y, en algunos casos, de asistencia en la recaudación. Así, la administración tributaria de un país adquiere la facultad de solicitar la información que requiera.

- Facilitan que la Administración, al conocer las estrategias que usan los agentes económicos internacionales, pueda detectar incumplimientos de obligaciones tributarias.

- Los convenios establecen métodos para aliviar o neutralizar la doble imposición, los cuales no pueden ser alterados para los países contratantes.

- Bajo ninguna circunstancia un convenio puede crear una obligación tributaria inexistente en la ley interna.

- El procedimiento amistoso, mediante el cual la Administración del propio país interviene en la solución de controversias, otorga seguridad al inversionista respecto de la protección de sus legítimos intereses.

- La inclusión del principio de no discriminación en un convenio garantiza al inversionista que, una vez que haya efectuado su inversión, el país no va a cambiar su política para obligar a los extranjeros a pagar más impuestos que los residentes. 


\subsubsection{Objetivos de los convenios}

Escobar et al., (2012), señala que los objetivos de la firma de convenios son los siguientes:

- Eliminar en forma completa la doble imposición, tomando en cuenta las características de los correspondientes sistemas fiscales, para ser gravada solo por un Estado o ambos en forma coordinada.

- Permitir una reducción de la doble imposición, con la renuncia a ciertos ingresos en sus funciones recaudatorias.

- Brindar mayor seguridad jurídica a los sujetos fiscales a los que se les aplica el convenio.

- Promover las relaciones económicas y comerciales entre las partes e incrementar también las transacciones.

- Combatir el fraude internacional por medio de supuestos normativos incluidos en las legislaciones tributarias.

\subsection{La interpretación de los convenios para evitar la doble imposición}

La interpretación es útil en toda aplicación del Derecho. La interpretación es el proceso por el cual se determina el sentido de las diferentes normas y conceptos que se han de aplicar para la solución de una controversia, como lo es la doble tributación. (Gragueda, 2010, p.56)

Cuando hablamos de la naturaleza de los convenios para evitar la doble imposición (en adelante, CEDT), podemos pensar que los mismos son una especie de un todo llamado "acuerdos internacionales en materia tributaria". Lo cierto es que los CEDT tienen la naturaleza de tratados internacionales cuya función es eliminar los conflictos de tributación originados por el ejercicio de la soberanía de dos o más Estados y el poder tributario de ambos sobre cierta operación generadora del impuesto. (Uckar, 2003, p.104)

En suma, los CEDT establecen reglas de reparto de derechos entre los países para gravar las situaciones a las que afecta el convenio, limitando la soberanía de los países. “Es la función de reconciliación de dos sistemas tributarios nacionales”. (Lenz, 1960, p.294) 
Como tratados internacionales, se trata de normas negociadas por Estados soberanos que tienen como objeto una autolimitación de su soberanía y que se rigen cada vez más por las directrices de organizaciones internacionales como la OCDE o la ONU. No vinculan por su fuerza jurídica, pero los Estados deciden aplicarlas por el prestigio o el peso internacional de los organismos que los dictan. Se trata de normas de interpretación elaboradas por instituciones internacionales como la OCDE o las Naciones Unidas a través de comités especializados. Las normas son creadas sin intervención directa del Poder Legislativo de cada país, por lo que si lo previsto en el MOCDE llegara a aplicarse a un Estado no parte, la soberanía de este podría verse afectada por tenerse que apegar a lo dispuesto por un instrumento en cuya creación o interpretación no participó. (Gragueda, 2010, p.104)

Aun cuando en los propios CEDT se puedan estipular interpretaciones para diversos términos, las partes no siempre negocian o llegan a un acuerdo sobre los mismos, como es el caso del término de residencia. Frente a ello, el MOCDE y sus comentarios son instrumentos que tratan de proporcionar uniformidad a sus significados de manera permanente. En este orden de ideas, sin que exista un órgano o autoridad supranacional que decida el sentido de algún término o la voluntad de las partes contratantes al firmar este tipo de convenios, resultarán aplicables mecanismos de interpretación fijados en otros convenios internacionales, como la Convención de Viena y los modelos de convenios sobre la doble imposición que los Estados adopten como base para elaborar sus propios CEDT. (Gragueda, 2010, p.104)

Surge entonces la pregunta de si dichos tratados internacionales deben interpretarse de acuerdo a los criterios de la Convención de Viena o según el MOCDE ${ }^{4}$. La prevalencia de la aplicación de la Convención de Viena, tal y como lo señala Díez de Velasco (1994) “Está avalada por la mayoría de los países y por la Comisión de Derecho Internacional, órgano subsidiario de las Naciones Unidas”. (p. 189)

En contra de la aplicación de los criterios contenidos en los artículos $31^{\circ}, 32^{\circ} \mathrm{y}$ $33^{\circ}$ de la Convención de Viena en la interpretación de los CEDT se sitúan aquellos autores como Calderón Carrero (2004), "Que entienden que las características específicas

\footnotetext{
${ }^{4}$ Modelo de Convenio Tributario Sobre la Renta y el Patrimonio de la Organización para la Cooperación y Desarrollo Económico
} 
de los CEDT requieren reglas especiales de interpretación que no coinciden propiamente con las reglas habituales de interpretación de Derecho Internacional público”. (p. 171)

En concreto, estos autores niegan que las disposiciones de la Convención de Viena sean adecuadas para la interpretación de los CEDT, haciendo énfasis en la improcedencia de la idea de contexto que se deduce del artículo $31^{\circ}$ de la citada Convención. (Gragueda, 2010, p.104)

Según el artículo $31^{\circ}$ de la Convención de Viena, "un tratado deberá interpretarse de buena fe, conforme al sentido corriente que haya de atribuirse a los términos del tratado en el contexto de estos y teniendo en cuenta su objeto y fin". La exigencia de interpretar los tratados de acuerdo con la buena fe supone: (i) otorgar preferencia a la interpretación que mejor se adecúe al cumplimiento de las obligaciones objeto del tratado; y (ii) cumplir el contenido de los tratados de acuerdo con una exigencia de equilibrio de intereses entre los firmantes. Esto último impediría que una de las partes obtuviera ventajas tributarias por la existencia de expresiones ambiguas en el texto del tratado. (Condon, 2007)

\subsection{CDI suscritos por el Perú}

Los CDI son acuerdos que celebran dos o más países, teniendo en cuenta las relaciones comerciales internacionales que realizan sus ciudadanos, con la finalidad de repartir la potestad de gravar determinada renta a efectos de evitar que sea gravada por dos o más países.

Es preciso señalar que los CDI no crean o regulan tributos, tampoco establecen supuestos gravados y tasas, solo conceden la potestad de gravar a uno u otro Estado según lo estipulado en el convenio.

Es importante la suscripción de convenios; en ese sentido, como señala Renee Villagra (2008):

Desde una perspectiva global, produce una serie de efectos importantes para la economía en desarrollo, entre otros, un mayor flujo de capitales, el que redunda en una profundización y diversificación de las actividades transnacionales, especialmente respecto de actividades que involucra tecnología avanzada y asesorías técnicas de alto nivel. (p. 171)

Actualmente, el Estado peruano tiene firmados siete CDI, que citamos a continuación con la fecha de inicio de su aplicación: 
Tabla 2.1.

Convenios para evitar la doble imposición celebrados por el Perú

\begin{tabular}{|c|c|c|c|c|c|c|c|}
\hline & Chile & Canadá & Brasil & $\begin{array}{c}\text { Corea del } \\
\text { Sur }\end{array}$ & México & Portugal & Suiza \\
\hline $\begin{array}{c}\text { Fecha } \\
\text { en que } \\
\text { surte } \\
\text { efectos }\end{array}$ & $1 / 1 / 2004$ & $1 / 1 / 2004$ & $1 / 1 / 2010$ & $1 / 1 / 2015$ & $1 / 1 / 2015$ & $1 / 1 / 2015$ & $1 / 1 / 2015$ \\
\hline
\end{tabular}

Fuente: Superintendencia Nacional de Administración Tributaria (2015). Recuperado de: http://www.un.org/esa/ffd/wp-content/uploads/2015/07/2015PTB_3Peru.pdf

Si bien, de acuerdo a lo ya señalado, los CDI no crean tasas, sí contemplan tasas máximas, que en virtud de la aplicación del convenio deben ser respetadas por los países que los suscriben. A continuación mostraremos las tasas máximas de retención en los CDI celebrados por el Estado peruano:

Tabla 2.2.

Tasas máximas de retención

\begin{tabular}{|c|c|c|c|c|c|c|c|}
\hline & Chile & Canadá & Brasil & $\begin{array}{c}\text { Corea del } \\
\text { Sur }\end{array}$ & México & Portugal & Suiza \\
\hline Dividendos & $10 \% / 15 \%$ & $10 \% / 15 \%$ & $10 \% / 15 \%$ & $10 \%$ & $10 \% / 15 \%$ & $10 \% / 15 \%$ & $10 \% / 15 \%$ \\
\hline Intereses & $15 \%$ & $15 \%$ & $15 \%$ & $15 \%$ & $15 \%$ & $10 \% / 15 \%$ & $15 \%$ \\
\hline Regalías & $15 \%$ & $15 \%$ & $15 \%$ & $15 \%$ & $15 \%$ & $10 \% / 15 \%$ & $15 \%$ \\
\hline $\begin{array}{l}\text { Asistencia } \\
\text { técnica }\end{array}$ & $15 \%$ & & - & $10 \%$ & - & $10 \%$ & $10 \%$ \\
\hline $\begin{array}{l}\text { Servicios } \\
\text { digitales }\end{array}$ & $15 \%$ & - & - & - & - & - & $10 \%$ \\
\hline
\end{tabular}

Fuente: Superintendencia Nacional de Administración Tributaria (2015). Recuperado de

http://www.un.org/esa/ffd/wp-content/uploads/2015/07/2015PTB 3Peru.pdf

\subsection{Decisión 578 de la Comunidad Andina}


La Comunidad Andina de Naciones está conformada por cuatro países sudamericanos (Bolivia, Colombia, Ecuador y Perú), los cuales decidieron unirse voluntariamente con el objetivo de alcanzar un desarrollo más acelerado, más equilibrado y autónomo, mediante la integración andina.

El 26 de mayo de 1969, en cumplimento de su objetivo, suscribieron el acuerdo de Cartagena, cuya finalidad era mejorar el nivel de vida de los ciudadanos de los países que la conforman, a través de la integración, y la cooperación social y económica, con lo cual se inició el proceso andino de integración.

Ya en el año 1971, los países miembros de la CAN celebraron la Decisión 40, la cual fue el primer convenio multilateral para evitar la doble tributación, adoptando el modelo de convenio de la ONU, decisión que adopta el criterio de la fuente.

La decisión 40 recogió el principio de la fuente, dado que dispuso que, independientemente de la nacionalidad o domicilio de las personas o entidades, las rentas de cualquier naturaleza que obtuvieran solo serían gravables en el país miembro en el que tales rentas tenían su fuente productora, salvo algunos casos de excepción, como son las utilidades o beneficios de las empresas de transporte, las ganancias de capital y las rentas provenientes de algunos servicios personales. En estos casos se utiliza el criterio del domicilio del sujeto pasivo. (Villagra, 2008, p.26)

El principio básico de la Decisión 578 de la Comunidad Andina está contenido en el artículo $3^{\circ}$, según el cual precisa que "independientemente de la nacionalidad o domicilio de las personas, las rentas de cualquier naturaleza que estas obtuvieren, solo serán gravables en el país miembro en que tales rentas tengan su fuente productora"5.

Además, dicho dispositivo señala que los demás países miembros que, de conformidad con su legislación interna, se atribuyan potestad de gravar las referidas

${ }^{5}$ Artículo 3.- Jurisdicción Tributaria

Independientemente de la nacionalidad o domicilio de las personas, las rentas de cualquier naturaleza que éstas obtuvieren, sólo serán gravables en el País Miembro en el que tales rentas tengan su fuente productora, salvo los casos de excepción previstos en esta Decisión.

Por tanto, los demás Países Miembros que, de conformidad con su legislación interna, se atribuyan potestad de gravar las referidas rentas, deberán considerarlas como exoneradas, para los efectos de la correspondiente determinación del impuesto a la renta o sobre el patrimonio. 
rentas deberán considerarlas como exoneradas para los efectos de la correspondiente determinación del Impuesto a la Renta o sobre el patrimonio.

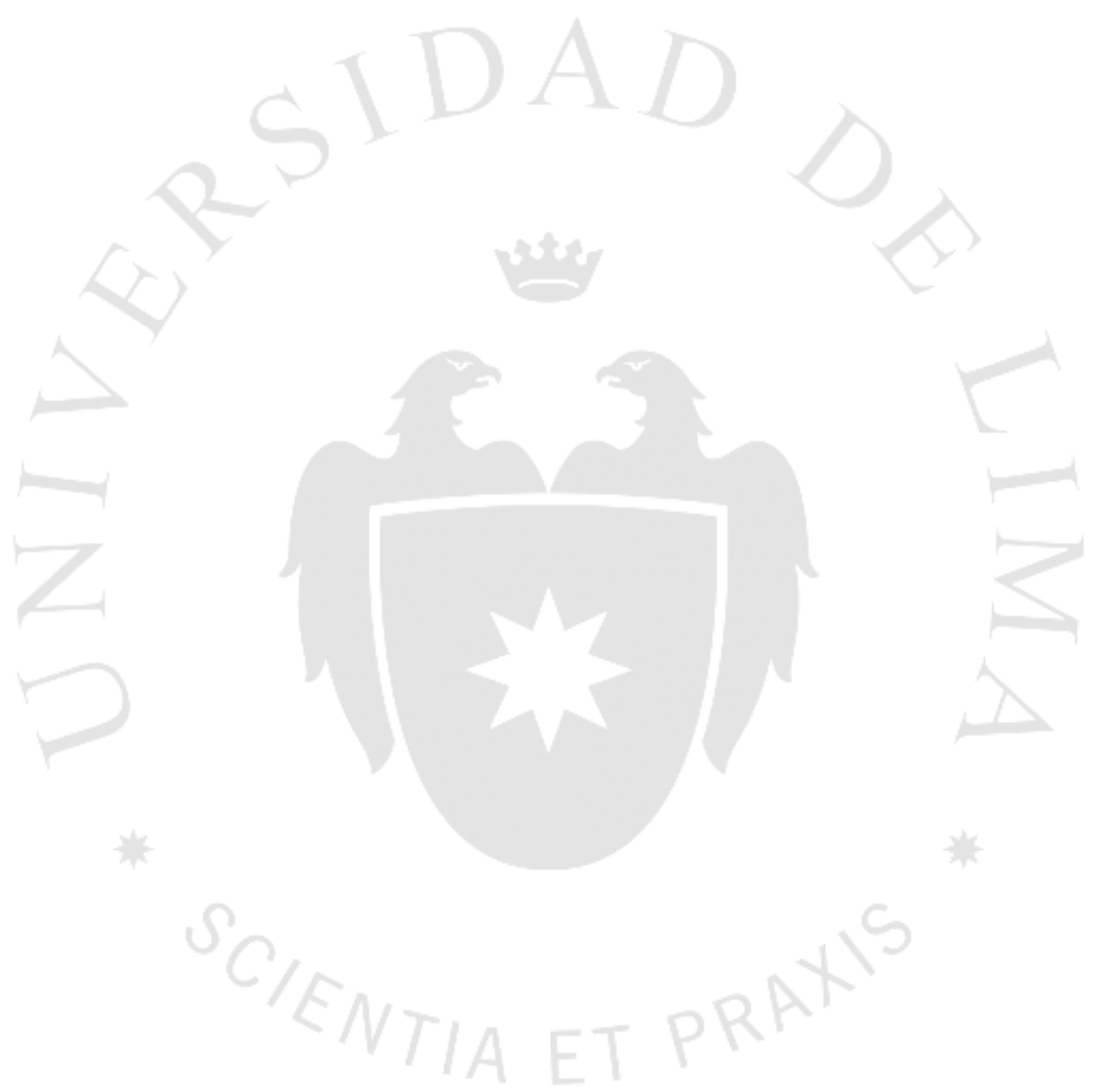




\section{CAPÍTULO III: LA DOBLE NO IMPOSICIÓN EN LA APLICACIÓN DE LOS CDI Y LA DECISIÓN 578 DE LA \\ CAN}

\subsection{Definición de doble no imposición}

La doble no imposición o nula imposición surge a nivel internacional cuando el Estado que goza de la potestad impositiva conforme a las cláusulas de un CDI no hace uso de este derecho en razón de su legislación interna (que concede una exención o no contiene una disposición que grave el hecho) y el otro Estado contratante carece de potestad impositiva en virtud al propio Convenio, o cuando uno de los Estados contratantes tiene conflicto de calificación (elemento material) o un conflicto de atribución (elemento subjetivo), quedando involuntariamente una renta sin someterse a imposición. (Danon, Robert y Salomé, 2010)

La no imposición presupone la ausencia de una norma tributaria aplicable, ya sea porque esta no existe (no imposición interna) o porque, existiendo, no es aplicable al hecho por una renuncia convencional al ejercicio de la potestad tributaria producto de la suscripción del CDI (no imposición internacional). (Bravo, 2013, p.170)

De una evaluación a la materia en cuestión, es de advertirse que las causas de no imposición derivada de la aplicación de un CDI en materia de impuestos a la renta pueden ser las siguientes: (Xavier, 2004, p.225)

a) El Estado de la residencia/fuente cede la potestad tributaria respecto de cierta ganancia al Estado de la fuente/residencia, pero este último no tiene disposiciones normativas internas que graven dicha ganancia.

b) El Estado de la residencia/fuente cede la potestad tributaria respecto de cierta ganancia al Estado de la fuente/residencia, pero este último tiene disposiciones normativas internas que establecen exenciones sobre dicha ganancia.

c) El Estado de la residencia/fuente cede la potestad tributaria respecto de cierta ganancia al Estado de la fuente/residencia, pero en aplicación del CDI la ganancia 
es recalificada a un supuesto que de acuerdo al convenio no se encuentra sometido a imposición.

d) De acuerdo a la ley local del Estado de la residencia/fuente, la renta es atribuida a un contribuyente diferente que no puede ser gravado en este Estado de acuerdo con el tratado.

Una interrogante sería ¿de producirse este fenómeno de doble no imposición, estamos frente a una elusión o una evasión tributaria internacional?

En cierta doctrina española la elusión tributaria empieza donde termina la economía de opción, en cambio, la evasión fiscal internacional sí comprende la simulación absoluta e, inclusive, la simulación relativa que afecta al fisco (como tercero). (Zavaleta, 2008, p.757)

De acuerdo a Mariano Braccia (2012):

La economía de opción describe la situación en la que el contribuyente tiene derecho a gozar de un beneficio tributario concedido por ley tributaria. Tanto la letra como el espíritu de la ley tributaria le ofrecen al contribuyente un beneficio que puede ser legítimamente aprovechado por aquel. Quedan, por lo tanto, a resguardo de todo cuestionamiento las acciones implementadas por los contribuyentes destinadas a obtener un ahorro fiscal mediante la legítima planificación fiscal. . (p. 65)

La elusión tributaria, por el contrario, se adentra en el territorio de lo reprochable aunque no implique una transgresión de la regla jurídica tributaria. Aquellos operadores no aferrados a posiciones textualistas estrictas aceptaran con mayor facilidad la explicación habitual que sostiene que las conductas elusivas transgreden el espíritu de la ley, bien que no su letra. (Braccia, 2012, p.65)

Somos de la opinión de que la doble no imposición se encuentra en una línea muy delgada entre la elusión y la economía de opción, situación que debería estudiarse a efectos de poder evitarla.

En doctrina encontramos el principio del impuesto único, que, como señala Diane Ring: "El principio del impuesto único ordena gravar la ganancia una sola vez, ni más ni menos, por lo que busca evitar los efectos tanto de la doble imposición como los de la doble no imposición”. (Ring, 2007, p.105) 
Los casos de doble no imposición se presentan cuando ni el Estado de residencia ni el Estado de la fuente gravan las ganancias en cuestión, porque ni uno ni otro ejercen sus facultades primarias de imposición. De esta forma, le asistiría a cualquiera de los Estados de residencia o de la fuente el derecho a ejercer una "imposición residual" a fin de prevenir la subimposición o la doble no imposición internacional. (Avi-Yonah, 2007, p.9)

Asimismo, Reuven Avi-Yonah (2007) sostiene:

Que los fundamentos teóricos del impuesto único buscan evitar que el régimen de tributación internacional genere un incentivo para invertir en el Estado de residencia, debido a los prejuicios provocados por una doble imposición internacional; o, a la inversa, incline la elección a favor de la inversión extranjera, en busca de una subimposición o doble no imposición. (p.259)

\subsection{Efectos en la aplicación de los CDI}

\subsubsection{Doble no imposición en aplicación de los CDI firmados en el marco del MCOCDE}

La doble no imposición en el marco de los convenios para evitar la doble o múltiple imposición es un fenómeno que se produce cuando respecto de una misma renta, por aplicación del convenio, un Estado contratante le concede la potestad tributaria al otro Estado contratante, pero este último no la grava, por no estar dentro del campo de aplicación según su norma doméstica.

Según Grozzo y Picón (2008):

En caso de que una persona natural o jurídica genere rentas en más de un país, estas se encuentran potencialmente sujetas a tributar en más de una jurisdicción, llevándose a cabo situaciones de doble o múltiple imposición internacional.

Estas situaciones de doble o múltiple imposición se presentan, principalmente, cuando dos o más países pretenden ejercer su potestad tributaria sobre la misma persona, por la misma renta y por el mismo periodo. (p.624)

Para afrontar este problema, se plantean mecanismos utilizados por el Derecho Tributario Internacional, con la finalidad de aliviar y/o evitar la doble o múltiple 
imposición internacional, y para regular esta situación se suscriben CDI entre dos o más países que establecen distintas atribuciones de manera recíproca sobre su soberanía, de modo que uno de ellos renuncia en forma parcial o total a su potestad tributaria.

En la aplicación de un CDI surgen posiciones controvertidas y fenómenos jurídicos no esperados. Uno de estos fenómenos es la denominada doble no imposición, según Bravo (2003), la no imposición o no sujeción es un fenómeno por el cual un hecho realizado en el plano fáctico no encaja en la descripción contenida en el presupuesto de hecho de la norma tributaria, no generándose efecto jurídico alguno. La no imposición no es un fenómeno jurídico, más si uno social (pp.249-250).

Según Bravo (2013):

En esencia, la doble no imposición presupone la ausencia de una norma tributaria aplicable, ya sea porque esta no existe (no imposición interna) o porque, existiendo, no es aplicable al hecho por una renuncia convencional al ejercicio de la potestad tributaria producto de la suscripción del CDI, al ejercicio de la potestad tributaria (no imposición internacional). En este último supuesto, el hecho de que producto de la suscripción de un convenio, uno de los Estados contratantes haya declinado su potestad tributaria respecto del otro Estado contratante, en cuanto a cierto hecho que en principio sometía a imposición, implica que hay una ausencia de norma respecto de dicho hecho, lo que viene a ser una no imposición. (p.170)

Cabe señalar que la eliminación de la doble no imposición no es un propósito perseguido por el Modelo de Convenio OCDE; por lo tanto, si uno de los Estados se ve impotente para ejercitar sus derechos a la imposición conforme al convenio, y el otro Estado contratante no establece impuestos sea por restricciones domésticas o por ausencia de normas domésticas, es completamente claro y evidente que la doble no imposición es el resultado de la aplicación del convenio. ("La Doble no Imposición en el Marco de los CDI" 2012)

En ese sentido, no se podría priorizar la aplicación de una norma del ordenamiento interno de alguno de los Estados contratantes en desmedro de la aplicación de un CDI, que en rigor constituye una norma supranacional con mayor jerarquía, y no aplicarlo implicaría una violación al principio pacta sunt servanda, según el artículo $26^{\circ}$ de la Convención de Viena, el cual señala que todo tratado en vigor obliga a las partes y debe 
ser cumplido por ellas de buena fe. ("La Doble no Imposición en el Marco de los CDI", 2012)

Por su parte, Bravo (2013) señala lo siguiente:

Si a través de un CDI, un Estado contratante renuncia en un caso concreto al ejercicio de su potestad tributaria en favor del otro Estado contratante, y este último por alguna de las razones (regulación doméstica, por ejemplo) no ejerce su potestad tributaria, creemos que no habrá forma de calificar dicha situación como antijurídica”. . (p.173)

El mismo autor cree que si un Estado contratante pretende prevenir los supuestos de no imposición que pudieran generarse de la aplicación de un CDI, deberán incluirse cláusulas de tributación efectiva en el otro Estado contratante o, en todo caso, perfeccionar sus convenios a efectos de evitar casos de no imposición no deseados.

Actualmente existe un intenso debate en torno al fenómeno de la doble no imposición, sin poder determinarse una solución general a este problema; la OCDE está trabajando en este sentido recogiendo aportes de la doctrina internacional para fijar lineamientos en su jurisdicción.

En el año 2013, la OCDE había adoptado el ambicioso Plan BEPS, que perseguía, inter alia, evitar las situaciones de "doble no imposición" en un contexto internacional, que, entre otras vías, podrían producirse a través de la utilización por parte de las empresas multinacionales de los denominados instrumentos financieros híbridos, aprovechando los desajustes en su tratamiento fiscal en las distintas jurisdicciones. Los instrumentos financieros híbridos se caracterizan por combinar elementos característicos de deuda con elementos característicos de capital, de modo que su calificación resulta una tarea compleja, sobre todo cuando su distribución se produce en un contexto internacional. En este escenario puede producirse una situación de "doble no imposición" o desimposición global si, por ejemplo, el Estado de la fuente considera tales rendimientos como intereses, permitiendo su deducción en cabeza de la entidad pagadora, mientras que el Estado de la residencia de la entidad perceptora los califica, a efectos fiscales, como dividendos, declarándolos exentos. Esta situación de desimposición a nivel global no es deseable desde la perspectiva de principios constitucionales de justicia tributaria y, además, puede revelar una situación de fraude y abuso, generando una tributación incoherente a nivel global. ("La tributación de los dividendos intersocietarios transnacionales en el ordenamiento jurídico español en la era post-BEPS”, 2016) 
En ese sentido, Núñez (2010) señala:

La distinción entre los conceptos de "deuda" y "capital" adoptada por las legislaciones del Impuesto a la Renta es una fuente de inconsistencias y abre la posibilidad de obtener importantes beneficios tributarios.

La estructuración de un instrumento financiero hibrido a nivel internacional puede originar que un rendimiento no se encuentre sujeto a tributación en ningún país. Si el país de la fuente califica el rendimiento como "interés" y el país de residencia lo considera "dividendo" se producirá el denominado "double dip effect", lo cual implica que el deudor reduce el "interés" en el país de la fuente, y el acreedor no se encuentra, en principio, gravado por los “dividendos” recibidos en su país de residencia (p. 179).

Adicionalmente a este fenómeno encontramos otro problema, que es el Trety Shopping, que de acuerdo a lo señalado por Zavaleta (2008):

El Trety Shopping para la corriente de autores españoles y la propia OCDE es el "abuso del derecho con fines elusorios de tributos", por cuanto se crea una "sociedad instrumento" en un Estado signatario con el solo propósito de aprovechar las ventajas que el convenio atribuye a los residentes de los Estados contratantes.

El acto orientado a usar un instrumento (interponiendo una empresa) sobrepasando los límites "normales" (saliendo de los fines intrínsecos del CDI), no puede ser aprovechado por quienes no tienen un vínculo subjetivo real con uno de los países signatarios, empero, si y solo si, dicha interposición está alejada de los caracteres de la simulación absoluta o relativa. Así lo califica García Novoa, para quien “(...) en concreto, es una expresión de una forma abusiva peculiar, como es la interposición de personas jurídicas.

Esto es, la creación real de una sociedad que excluya la simulación, pero que carece de contenido social, empresarial o económico”. De ahí que, se le llame también al treaty shopping a la interposición abusiva de sociedades para beneficiarse de un CDI del cual el maximizador fiscal no es residente directamente. (pp. 774-775)

Asimismo, se ha visto que en el ámbito deportivo también se ha ido utilizado esta figura como parte de un planeamiento tributario, con la única finalidad de lograr el ahorro fiscal a través de una disminución en la tributación e inclusive logrando una nula imposición, situación que está siendo combatida por los diferentes países que se han visto 
perjudicados por esta práctica abusiva al utilizar la interposición de una tercera sociedad para poder acceder a los beneficios que concede la suscripción de los convenios.

En la actualidad tenemos el caso del jugador del Barcelona Leonel Messi, que mediante una compleja maniobra negocial eludió el pago de los ingresos percibidos por la explotación de los derechos de imagen.

A tal efecto, se simularon una serie de operaciones que se fueron sucediendo en el tiempo y que tenían como elemento característico un engaño a la hacienda, materializado en una ocultación maliciosa de datos físicamente relevantes. ${ }^{6}$

En nuestra opinión, creemos que incluir cláusulas de tributación efectiva podría ser una de las posibles soluciones; en todo caso, los países que se vean afectados deberán negociar la firma de los convenios a los efectos que por evitar una nula imposición terminen favoreciendo los impuestos para un país contratante en detrimento del otro país contratante en aplicación del convenio para evitar la doble imposición.

Debemos considerar que en los últimos convenios firmados por el Perú, en algunos artículos se han introducido cláusula de sujeción, con la finalidad de evitar que una renta correspondiente a un contribuyente por un mismo periodo termine originando el fenómeno de doble no imposición.

Los convenios firmados y vigentes en nuestro país, además de los artículos, también cuenta con protocolos, estos últimos contienen alances que por alguna razón no se señalaron en los artículos, y que son muy importantes tenerlos en cuenta en el momentos de aplicar los convenios.

Esta cláusula la tenemos en el numeral 5 del Protocolo del CDI Perú-México respecto, única y exclusivamente, a intereses y ganancias de capital. Dicha cláusula señala que las disposiciones referidas a tales rentas, no se aplicarán si el perceptor de las mismas, siendo residente de un Estado Contratante, no está sujeto a imposición o está exento en relación con tales rentas de acuerdo con las leyes de ese Estado Contratante. En ese caso, estas rentas pueden estar sujetas a imposición en el otro Estado Contratante ${ }^{7}$.

\footnotetext{
${ }^{6}$ Procedimiento abreviado 110/15, Audiencia Provincial Barcelona, España.

7 5. Artículos 11 y 13

Las disposiciones de esos Artículos no se aplicarán si el perceptor de la renta, siendo residente de un Estado Contratante, no está sujeto a imposición o está exento en relación con esa renta de acuerdo con las leyes de ese Estado Contratante. En este caso, esta renta puede estar sujeta a imposición en el otro Estado Contratante
} 
Esta cláusula de sujeción también los encontramos en los CDI aplicable a las rentas por pensiones del artículo 18 suscritos por Perú con Suiza y Portugal, cláusula establecida en el inciso b) del numeral 12 del Protocolo en el CDI con Suiza; ${ }^{8}$, en el numeral 8 del Protocolo del CDI con Portugal ${ }^{9}$.

Si bien la Decisión 578 no contiene una cláusula de sujeción expresa, el Tribunal de Justicia de la Comunidad Andina ha interpretado su artículo $20^{\circ 10}$, evitando el riesgo de no imposición dentro de la Comunidad Andina para el caso del impuesto al patrimonio colombiano, al exigir la verificación previa de la doble imposición en los otros países miembros, como requisito para aplicar la referida Decisión. ("Planificación transnacional agresiva y abuso de tratados: Herramientas de derecho Interno y derecho internacional para contrarrestarlos en la era BEPS, 2017)"

Nuestro país, deberá considerar cada una de las situaciones de doble imposición que se han ido generando en convenios firmados entre otros países, y bajo esa experiencia deberá tener en cuenta dichas situaciones para efectos de que pueda ser tomado en cuenta cuando se negocie convenios en el futuro y así no nos veamos perjudicados por estas malas prácticas de algunos contribuyentes que conlleva a perder recaudación al Estado.

\subsubsection{Doble no imposición en el marco de la Decisión 578 de la CAN}

Según Grozzo y Picón (2008) señalan:

8 12. Ad Artículos 18 y 19

b) Cuando de acuerdo con el Artículo 18 del presente Convenio, las pensiones queden exentas del pago de impuestos en un Estado Contratante, y de acuerdo con la ley vigente en el otro Estado Contratante esas pensiones no estén efectivamente gravadas en este otro Estado Contratante, el Estado Contratante mencionado en primer lugar podrá gravar las pensiones con la tasa legal prevista en su legislación nacional.

${ }^{9}$ 8. Con referencia al Artículo 18

Se acuerda que, no obstante las disposiciones del Artículo 18 del Convenio, las pensiones, anualidades y otras remuneraciones similares pagadas a un residente de un Estado Contratante pueden también someterse a imposición en el Estado Contratante del que deriven, en la medida en que no estén sometidas a imposición en el Estado Contratante mencionado en primer lugar.

${ }^{10}$ Artículo 20.- Interpretación y Aplicación

La interpretación y aplicación de lo dispuesto en esta Decisión se hará siempre de tal manera que se tenga en cuenta que su propósito fundamental es el de evitar doble tributación de unas mismas rentas o patrimonios a nivel comunitario.

No serán válidas aquellas interpretaciones o aplicaciones que permitan como resultado la evasión fiscal correspondiente a rentas o patrimonios sujetos a impuestos de acuerdo con la legislación de los Países Miembros.

Nada de lo dispuesto en esta Decisión impedirá la aplicación de las legislaciones de los Países Miembros para evitar el fraude y la evasión fiscal. 
La doble no imposición en el marco de la Decisión 578 de la Comunidad Andina de Naciones se produce cuando en ciertas circunstancias algunos conceptos supuestamente afectos al Impuesto a la Renta quedan sin estar sujetos a gravamen.

Este convenio multilateral suscrito por los países miembros de la CAN tiene como perspectiva la armonización de las normas tributarias y la integración a nivel comunitario, a fin de disminuir el impacto fiscal originado en las operaciones comerciales cuando concurren dos o más potestades tributarias, teniendo como consecuencia que uno de los Estados miembros renuncie en forma total o parcial a su potestad tributaria. En tal sentido, tratándose de los impuestos a la renta y sobre el patrimonio, la Decisión 578 ha establecido que las rentas atribuibles a personas domiciliadas dentro de la CAN solo serán gravables en el país miembro en que tales rentas tengan su fuente productora, lo que ha originado determinadas situaciones en que, en lugar de evitar la doble imposición, se produce una doble no imposición o nula imposición. (pp. 617-618)

El Perú, al ser integrante de la Comunidad Andina de Naciones, está sujeto a las disposiciones de la Decisión 578, vigente desde el 1 de enero de 2005, la cual contiene un convenio multilateral para evitar la doble imposición internacional entre sus miembros.

Se diferencia del esquema de atribución de rentas seguido por el Modelo OCDE, bajo el cual las rentas pasivas suelen atribuirse al país de residencia y las activas al país de la fuente; en cambio, la Decisión 578 ha optado por establecer un régimen a través del cual las rentas son gravadas únicamente por el país de la fuente, debiendo el país de la residencia “(...) considerarlas como exoneradas, para los efectos de la correspondiente determinación del impuesto a la renta o sobre el patrimonio", de acuerdo al artículo $3^{\circ}$ de la Decisión.

En ese sentido, cada uno de los artículos de la Decisión 578 tienen por finalidad establecer criterios para determinar cuál es el país de la fuente con respecto a cada categoría de renta y, por tanto, atribuirle a este exclusiva competencia para gravar ciertas operaciones con el impuesto a la renta.

El fenómeno de la doble no tributación puede ocurrir como consecuencia de la aplicación de la legislación interna o cuando los Estados aceptan reconocer que solamente uno de ellos tiene exclusiva competencia, pero el Estado competente no la ejercita en realidad debido a una previsión de su propia ley nacional (la doble no imposición por 
razones de ley doméstica que no contiene una disposición que permita que grave esta renta).

Este fenómeno no previsto puede ocurrir también por un conflicto de interpretación cuando uno de los Estados interpreta que las cláusulas del tratado conceden competencia exclusiva al otro Estado contratante, pero este último interpreta la misma cláusula de manera diferente, es decir, considera que no tiene competencia exclusiva, y en este supuesto, la doble no imposición es atribuible al conflicto en la interpretación del Convenio. (Grozzo y Picón, 2008, p.619)

La decisión 578 de la Comunidad Andina, entre uno de sus objetivos es el combatir la doble imposición entre sus países miembros, pero no ha previsto mecanismos para evitar supuestos que se producen ya sea por omisión o defecto de técnica legislativa, lo que está originando que una determinada renta quede sin estar sometida a gravamen entre los Estados contratantes.

\subsection{El proyecto BEPS y su aplicación a supuestos de doble no imposición}

La Organización para la Cooperación y Desarrollo Económicos (con sus siglas en español, OCDE), en su afán de promover y mejorar el bienestar económico, ha establecido un plan de acción que busca evitar la erosión de bases imponibles y traslación de beneficios. (“Organización para la Cooperación y el Desarrollo Económicos”, 2014)

Se necesitan cambios fundamentales para evitar eficazmente la doble exención, así como los supuestos de exención o baja imposición asociados a prácticas que separen artificiosamente los ingresos imponibles de las actividades que los generaron. (“'Organización para la Cooperación y el Desarrollo Económicos”, 2014)

Se pueden adoptar una serie de medidas para abordar la debilidad de las normas actuales de un modo eficaz y eficiente. Este plan de acción demanda cambios fundamentales en los mecanismos actuales y la adopción de nuevos enfoques basados en el consenso, incluyendo disposiciones antiabuso, diseñados para evitar y contrarrestar la erosión de la base imponible y el traslado de beneficios. (“Organización para la Cooperación y el Desarrollo Económicos", 2014)

Con el tiempo, la normativa actual también ha revelado debilidades que crean oportunidades para la erosión de la base imponible y el traslado de beneficios. La erosión 
de la base imponible y el traslado de beneficios se relacionan sobre todo con ejemplos en los que las diferentes normas impositivas producen una doble exención o una imposición inferior a la ordinaria. También se relacionan con estructuras artificiosas que logran una baja o nula imposición mediante la retirada de los beneficios de las jurisdicciones donde tienen lugar las actividades que los generan. La baja o nula imposición no son per se causa de preocupación, pero sí lo son cuando están asociadas a prácticas que disocian artificiosamente la base imponible de las actividades que la generaron. En otras palabras, lo que crea preocupación a la política impositiva es que, debido a lagunas en la interacción de distintos sistemas impositivos, en algunos casos derivados de tratados de doble imposición, los beneficios de las actividades transfronterizas puedan quedar sin gravar o quedar, sin razón, insuficientemente gravados. (“Organización para la Cooperación y el Desarrollo Económicos”, 2014)

De acuerdo a lo señalado, somos de la opinión de que estas debilidades reveladas deben ser combatidas por todos los países que forman parte de la OCDE, para lo cual todos los países deberían exponer cada uno de los supuestos de doble no imposición que han detectado en aplicación de los convenios, y de esta manera poder analizarlos y encontrar mecanismos de solución cuando se suscite este tipo de problemas; lo que se busca es una tributación justa en aplicación de la normativa internacional, ya que si por aplicación del CDI un Estado contratante concede la potestad de tributar al otro Estado contratante, este último deberá ejercerla aunque en su legislación doméstica esa operación no se encuentre gravada.

Ahora bien, el Plan de acción 6 contra la erosión de la base imponible y el traslado de beneficios titula "Impedir la utilización abusiva de convenio", el cual señala desarrollar disposiciones convencionales y recomendaciones relativas al diseño de normas internas que impidan la concesión de los beneficios del convenio en circunstancias inapropiadas. Se realizarán también trabajos para clarificar que los convenios fiscales no se destinan a ser empleados para generar la doble no imposición y para identificar las consideraciones de política fiscal que, en general, los países deben tener en cuenta antes de decidirse a entrar en un convenio fiscal con otro país. El trabajo se coordinará con el trabajo sobre híbridos. ("Organización para la Cooperación y el Desarrollo Económicos”, 2014)

La Organización para la Cooperación y el Desarrollo Económicos publicó el informe final 2015 del Plan de Acción 6, relacionado Impedir la utilización abusiva de convenios fiscales, 
ha desarrollado en la sección B una Aclaración de que los convenios tributarios no están concebidos para provocar doble no Imposición.

En ese sentido, como resultado del trabajo sobre la Acción 6, se introdujeron algunos cambios al Modelo de Convenio Tributario de la OCDE, así tenemos lo siguiente:

Reemplazar el encabezado "Preámbulo del Convenio" (incluida su nota al pie)

1. El Preámbulo del Convenio deberá redactarse de acuerdo con los procedimientos constitucionales de cada Estado contratante.

Por el siguiente: PREÁMBULO DEL CONVENIO

PREÁMBULO DEL CONVENIO

(Estado A) y (Estado B),

Deseando desarrollar sus relaciones económicas y fortalecer su cooperación en materia tributaria,

Con la intención de concluir un Convenio para la eliminación de la doble imposición en materia de impuestos sobre la renta y sobre el patrimonio sin que ello conlleve la generación de oportunidades para la doble no imposición o la imposición reducida a través de la elusión o la evasión fiscales (también a través de estrategias de treaty shopping — captación de convenios- que buscan obtener los beneficios previstos en este Convenio para el beneficio indirecto de residentes de terceros Estados). OCDE (2016), Impedir la utilización abusiva de convenios fiscales, Acción 6 - Informe final 2015, Proyecto de la OCDE y del G-20 sobre la Erosión de la Base Imponible y el Traslado de Beneficios, Éditions OCDE, Paris.

http://dx.doi.org/10.1787/9789264257085-es

Entonces, queda claro que la celebración de convenios no debería ser utilizado como una herramienta que busca oportunidades para una doble no imposición o minimización de impuestos.

\subsection{Planeamiento fiscal agresivo}

Hoy en día, muchas empresas que se encuentran establecidas en distintitas jurisdicciones del mundo, buscan de alguna manera minimizar sus costos tributarios, valiéndose para ello de grandes estudios jurídicos a quienes encargan la tarea de buscar mecanismos que 
les permitan encontrar algunos vacíos en las legislaciones tributarias en aplicación de los convenios a efectos de poder lograr un ahorro fiscal en los países donde operarán.

El reciente paradigma empresarial de cadena de valor global coadyuva a la concepción de prácticas elusivas, constituidas en la planeación fiscal de grupos multinacionales; así lo han expresado los estudiosos de esta nueva era de la tributación, en la cual prima el interés por sujetar a imposición la riqueza generada por empresas con modelos de negocios globales y prevenir supuestos de no imposición; esto es, regular las estrategias de planeación fiscal internacional, pues mediante esta figura las corporaciones transnacionales buscan el máximo de beneficios de la normativa de los Estados donde operan, actuando de manera agresiva a través de mecanismos artificiosos a fin de evadir sus obligaciones impositivas. ("Revista de Fiscalidad Internacional y Negocios Transnacionales", 2017)

La planeación fiscal de alcance global es resultado de la creciente competencia y cooperación internacional en el campo de la tributación; por un lado, la reducción de tasas impositivas y el otorgamiento de incentivos fiscales en nombre de los gobiernos impulsa en las empresas multinacionales ubicar las operaciones económicas -tanto de producción como administrativas- que constituyen el grupo empresarial en jurisdicciones donde mayor convenga a sus intereses; por otro lado, a través de la red de convenios para evitar la doble imposición, las compañías multinacionales trasladan su riqueza a países con menor tasa impositiva a rendimientos, situando gastos en territorios con altas cargas tributarias. . ("Revista de Fiscalidad Internacional y Negocios Transnacionales”, 2017)

En el marco de la Unión Europea, su comisión proponía en su plan de acción 12, una nueva iniciativa la cual destaca su recomendación sobre la planificación fiscal agresiva, respecto de la propuesta de introducir una cláusula antielusiva general doméstica y convencional.

Una iniciativa estructural de la Comisión Europea fue la propuesta de Directiva del Consejo relativa a una base imponible consolidada común del impuesto sobre sociedad (BICCIS), del 16 de marzo del 2011, básicamente, el régimen de la BICCIS consistía en un conjuntos de normas comunes destinadas al cálculo de la base imponible de las sociedades residentes a efectos fiscales en la $\mathrm{UE}^{11} \mathrm{y}$ de las sucursales de las sociedades de terceros países situadas en la UE, la determinación de los resultados

\footnotetext{
${ }^{11}$ Unión Europea
} 
fiscales individuales de cada sociedad (o de su sucursal), su consolidación en caso de que existan otros miembros del grupo y la distribución de la base consolidada entre cada uno de los Estados miembros admisibles. Así mismo, se preveía una serie de normas para la lucha contra el fraude.

En Europa, la Comisión Europea está trabajando buscando posibles soluciones a la problemática que origina los planeamientos tributarios agresivos, que está ocasionando disminución en recaudación en diversos países, sin embargo esta iniciativa propuesta por la Comisión de la Unión Europea a pesar de que es complicado que se haga realidad, para los países como el Perú sería muy difícil proponer una medida de tal magnitud, ya que nuestra realidad económica es muy diferente al de los países europeos, teniendo en cuenta que somos un país importador de capital a diferencia de los Europeos que son exportadores de capital, soluciones que de alguna manera tratan de proteger a los países residentes.

Sobre la base de lo comentado, la OCDE, a través de su plan de acción BEPS, busca luchar contra ciertos mecanismos que tratan de evitar que sus ingresos sean gravados en el país de la fuente o en el país de la residencia.

Adicionalmente, se está recomendando a muchos países revisar su normativa para evitar que las grandes empresas dejen de pagar sus impuestos. En el caso peruano, con el Decreto Legislativo $\mathrm{N}^{\circ} 1312$ (2016), se adecuó nuestra legislación a los estándares y recomendaciones internacionales emitidos por la Organización para la Cooperación y el Desarrollo Económico (OCDE) sobre el intercambio de información para fines tributarios, fiscalidad internacional, erosión de bases imponibles, precios de trasferencia y combate contra la elusión tributaria, teniendo en cuenta el inciso $\mathrm{C}$ del Capítulo $\mathrm{V}$ de las directrices sobre la documentación de los precios de transferencia. ${ }^{12}$

\footnotetext{
${ }^{12} \mathrm{C}$. Un enfoque en tres niveles de la documentación sobre precios de transferencia 16. Con objeto de lograr los objetivos descritos en la sección $\mathrm{B}$, los países deben adoptar un enfoque estandarizado en cuanto a la documentación sobre precios de transferencia.

Esta sección expone un sistema de tres niveles consistente en (i) el archivo maestro, que recoge información estandarizada correspondiente a todos los miembros del Grupo Multinacional; (ii) el archivo local que se refiere específicamente a las operaciones significativas del contribuyente local; y (iii) el informe país por país, que contiene cierta información acerca de la distribución mundial de los beneficios y los impuestos pagados, junto con determinados indicadores de la ubicación de la actividad económica dentro del Grupo Multinacional.

17. Este enfoque facilitará a las administraciones tributarias información fiable y pertinente para realizar una evaluación sólida y eficiente del riesgo de precios de transferencia.

Asimismo proporcionará una plataforma para ampliar la información necesaria para una inspección y ofrecerá a los contribuyentes un medio y un incentivo para analizar y describir coherentemente el cumplimiento por su parte del principio de plena competencia en las operaciones significativas.
} 
El intercambio de información entre Estados es una herramienta muy importante que permitirá combatir supuestos de doble no imposición. Hoy en día, el en su artículo $26^{\circ}$ del Modelo de la $\mathrm{OCDE}^{13}$, contempla de manera expresa el intercambio de información tributaria.

El Congreso americano aprobó la Ley FACTA, por la cual se crea un sistema de acuerdos entre las entidades financieras extranjeras y el Servicio de Renta Interna de los Estados Unidos, que le permitirá al Gobierno americano obtener información y saber si la entidad financiera extranjera (por ejemplo, un banco peruano) tiene como cliente a un contribuyente norteamericano. ("Los acuerdos de intercambio de información tributaria y su implementación en el Perú”, 2014).

Uno de los retos que plantean los convenios de intercambio es la observancia de los derechos del contribuyente a fin de lograr un equilibrio entre los intereses fiscales y el respeto de los derechos inherentes a la persona, específicamente de aquellos relacionados con el derecho a la intimidad, al secreto profesional, el secreto comercial o industrial; este trabajo no es sencillo, pues debe evitarse que las limitaciones establecidas puedan ser utilizadas por los contribuyentes para amparar conductas ilegales. Se recomienda entonces establecer de manera conjunta los mecanismos de protección de datos y la definición de las entidades que pueden tener acceso a la información obtenida. (“Los acuerdos de intercambio de información tributaria y su implementación en el Perú”, 2014).

En cuanto a la implementación de estos acuerdos en el Perú, la adopción ha sido lenta, lo que se evidencia con el pequeño número de CDI y de convenios administrativos entre administraciones tributarias que se han suscrito. En cuanto a la implementación de la Ley Facta en el Perú, esta es una realidad inexorable que eventualmente generará sobrecostos como consecuencia de las medidas de control que establezcan las entidades financieras, más allá del costo que significara la retención que se aplique sobre los pagos recibidos de fuente americana, aun cuando puedan ser objeto de posterior devolución por el físco americano. ("Los acuerdos de intercambio de información tributaria y su implementación en el Perú”, 2014).

\footnotetext{
${ }^{13}$ Las autoridades competentes de los Estados contratantes intercambiarán la información previsiblemente pertinente para aplicar lo dispuesto en el presente Convenio o para administrar y exigir lo dispuesto en la legislación nacional de los Estados contratantes relativa a los impuestos de toda clase y naturaleza percibidos por los Estados contratantes, sus subdivisiones políticas o entidades locales en la medida en que la imposición prevista en la misma no sea contraria al Convenio
} 
En ese sentido, a través de la firma de convenios o de acuerdos entre administraciones tributarias, tendremos la posibilidad de poder detectar posibles mecanismos que utilizan los contribuyentes a efectos de poder disminuir o anular la carga tributaria.

Por lo tanto, el Perú debería firmar una serie de tratados de intercambio de información que permitan detectar ingresos que no se están grabando en nuestro país, situación que a la par perjudica a los contribuyentes que sí tributan, quienes tendrán que soportar con mayor fuerza la carga fiscal que otros no asumen por las razones expuestas.

\subsection{Casuística relacionada a operaciones de doble no imposición}

En lo que concierne a los CDI, en el siguiente caso describiremos un supuesto de doble no imposición.

En aplicación del CDI firmado por Austria y España, el Tribunal Superior de Justicia de Navarra, el 16 de abril de 2001, se pronunció señalando que en el caso de los bonos austriacos, la no imposición de los intereses derivada de la aplicación del CDI suscrito entre Austria y España no representaba un fraude de ley, sino, por el contrario, un supuesto de lícita economía de opción que obedecía a una motivación económica perfectamente válida, racional, licita y legítima, como es el aprovecharse de la exención fiscal concedida por la República de Austria, y esto en uso del legítimo poder tributario que le condecía el CDI antes referido.

De acuerdo al artículo $24^{\circ}$ de la Ley General Tributaria Española, lo que caracteriza al fraude de ley tributaria es el hecho de que el sujeto pasivo, para producir un resultado equivalente al derivado del hecho imponible, se apoye en una norma dictada con distinta finalidad o, lo que es lo mismo, en una vía que no había sido contemplada por el legislador de modo específico en sus consecuencias fiscales o que no le había otorgado expresamente la ventaja fiscal que el sujeto pasivo pretendía obtener a través de la misma (Sentencia T.S.J. Navarra del 16 de abril de 2001).

En el fraude de ley el contribuyente no solo realiza operaciones o emplea negocios jurídicos diferentes a los normales o típicos, sino que, además, lo hace con abuso de las formas jurídicas; en definitiva, el fraude de ley no es otra que el ánimo de burlar una 
norma sirviéndose de otra dictada con finalidad diferente. (Sentencia T.S.J. Navarra del 16 de abril de 2001).

En dicho caso, en el CDI se atribuía a Austria la potestad de gravar los intereses de la deuda pública emitida por dicho país, el que a su vez había establecido una exención a favor de los intereses de deuda pública obtenidos por los no residentes. En ese sentido, la problemática se origina por la compra o venta de bonos austriacos que, al ser adquiridos por ciudadanos españoles, no tributaban en España en aplicación del convenio suscrito entre Austria y España, tal convenio concedía la potestad tributaria en lo que respecta a los intereses por bonos a los residentes austriacos, situación que originaba que los ciudadanos españoles no tributen ni en su país ni en Austria, generándose de esa manera este fenómeno de la doble no imposición. (Sentencia T.S.J. Navarra del 16 de abril de 2001).

Por otro lado, en la Decisión 578 de la Comunidad Andina, la doble no imposición la podemos describir en el siguiente caso:

Abarcaremos un caso planteado por la ponencia de Grozzo Costa y Picón Gonzáles (2008) en la revista IFA Perú, el tratamiento tributario de los pagos efectuados a un licenciante por la cesión de la licencia de uso de un software.

En primer lugar, debemos distinguir si la contraprestación por la cesión de un software constituye un pago por concepto de regalías o se trata de la retribución por la adquisición del mismo.

De acuerdo al Oficio $\mathrm{N}^{\circ}$ 00679-2005/ODA-INDECOPI, puede concluirse que el contrato de licencia de uso de software, así como sus actualizaciones, implica la cesión en uso de uno de los atributos del derecho de autor (realizar la reproducción de la obra por cualquier forma o procedimiento) a favor de un tercero (licenciatario) que paga por ello.

El primer párrafo del artículo $27^{\circ}$ del Texto Único Ordenado de la Ley del Impuesto a la Renta ${ }^{14}$ dispone que "cualquiera sea la denominación que le acuerden las partes, se considera regalía a toda contraprestación en efectivo o en especie originada por el uso o por el privilegio de usar patentes, marcas, diseños o modelos, planos, procesos o fórmulas secretas y derechos de autor de trabajos literarios, artísticos o científicos, así como toda contraprestación por la cesión en uso de los programas de instrucciones para

\footnotetext{
${ }^{14}$ D.S. No $179-2004-E F$ y normas modificatorias.
} 
computadoras (software) y por la información relativa a la experiencia industrial, comercial o científica".

Por su parte el artículo $16^{\circ}$ del Reglamento ${ }^{15}$ de la Ley de Renta precisa que cuando la contraprestación pagada por el tercero corresponde a la cesión definitiva, ilimitada y exclusiva de los derechos patrimoniales sobre el programa, se entiende configurada una enajenación. En cambio, la contraprestación calificará como regalía cuando se produzca una cesión parcial de los derechos patrimoniales sobre el programa para la explotación del mismo por parte del cesionario.

Si bien estas normas nos llevan a concluir que en el caso bajo análisis nos encontraríamos ante una cesión de uso de software que genera el pago de regalías, se debe tener que presente que mediante Informe $\mathrm{N}^{\circ}$ 311-2005-SUNAT/2B0000, emitido por la Intendencia Nacional Jurídica de Sunat el 22 de diciembre de 2005, la administración tributaria ha opinado lo siguiente:

I. Para los efectos del Impuesto a la Renta, en la adquisición de copias de software, la retribución que pagan los licenciatarios a los licenciantes respecto de contratos que impliquen la simple licencia de uso personal de tales programas para computadoras no califica como regalía.

II. En la adquisición de software hecho a la medida o de programas estandarizados, la retribución que se pague será la contraprestación a una enajenación de bienes, tratándose de adquisiciones que impliquen el simple otorgamiento de licencias de uso personal del software.

La Sunat ha opinado que en este caso nos encontramos ante una enajenación y no ante una regalía, de tal manera que un licenciante no domiciliado estaría fuera del campo de aplicación del Impuesto a la Renta al no generar renta de fuente peruana.

En consecuencia, tratándose de una licencia de uso de software conferida a un usuario peruano por un sujeto domiciliado en un país miembro de la CAN, la retribución correspondiente no estará gravada en ninguno de los dos países, produciéndose en este caso un efecto no deseado por este convenio. (pp. 622-624)

${ }^{15}$ D.S. N ${ }^{\circ} 122-94-E F$ y normas modificatorias. 
En ese sentido, somos de la opinión que este fenómeno de doble no imposición se produce por legislación interna y no por el criterio administrativo de la Sunat al aplicar la decisión 578.

En virtud a lo señalado, creemos que estaríamos ante un supuesto de doble no imposición si el servicio es calificado como venta, y es en esa línea el desarrollo del informe de Sunat, el cual está enfocado en un servicio que cumple con las características de una enajenación, por lo tanto por legislación interna estamos ante un supuesto de doble no imposición; de igual modo, es muy importante que la administración tributaria, antes de emitir sus informes, evalúe el impacto que sus actos pueden originar en su aplicación, ya que podría crear supuestos de nula imposición, vale decir, crea mecanismos que pueden ser utilizados por algunos contribuyente como un planeamiento tributario a efectos de disminuir o anular la tributación de los servicios prestados por no domiciliados.

Adicionalmente al caso anterior tenemos otro: el artículo $14^{\circ}$ de la Decisión 578 señala que las rentas obtenidas por empresas de servicios profesionales, técnicos, de asistencia técnica y consultoría serán gravables solo en el país miembro en cuyo territorio se produzca el beneficio de tales servicios; por lo que, salvo prueba en contrario, se presume que el lugar donde se produce el beneficio es aquel en el que se imputa o registra el gasto correspondiente ${ }^{16}$.

En efecto, si desde cualquier Estado miembro de la CAN se prestara un servicio diferente a una asistencia técnica a una empresa peruana, la renta correspondiente solamente debería encontrarse sujeta a imposición en el Perú, mas no en el país miembro de la CAN en el cual se prestó el servicio, dado que la empresa peruana contabilizará localmente el gasto correspondiente por dicho servicio. ("La Doble no Imposición en el Marco de los CDI” 2012)

Sin embargo, en aplicación de dicha Decisión, en ese escenario se daría origen al fenómeno de la doble no imposición en caso de que una empresa boliviana preste un servicio que no sea de asistencia técnica (en este servicio el criterio de conexión es la

\footnotetext{
${ }^{16}$ Artículo 14.- Beneficios empresariales por la prestación de servicios, servicios técnicos, asistencia técnica y consultoría Las rentas obtenidas por empresas de servicios profesionales, técnicos, de asistencia técnica y consultoría, serán gravables sólo en el País Miembro en cuyo territorio se produzca el beneficio de tales servicios. Salvo prueba en contrario, se presume que el lugar donde se produce el beneficio es aquél en el que se imputa y registra el correspondiente gasto.
} 
utilización económica, sin importar desde donde se prestó) a una empresa peruana, tal servicio no estaría sujeto a imposición en Bolivia, ya que por aplicación de la Decisión la potestad tributaria la tiene el Perú, pero en la legislación interna de este último se señala que las rentas que genera una empresa no domiciliada solo serán gravables por las rentas que se genere en el país; en ese sentido, al prestarse el servicio desde Bolivia, se estaría ante un servicio de fuente extranjera, y por tal motivo no está sujeto a imposición en el Perú. Ante esta situación se genera el fenómeno de la doble no imposición.

\subsection{Propuestas para evitar la doble no imposición en la aplicación de los convenios}

- Incluir en los convenios una cláusula especial de tributación con la finalidad de evitar que por aplicación de un CDI una determinada renta termine sin estar sujeta a gravamen en ninguno de los Estados contratantes.

- Incluir en nuestra legislación doméstica, una cláusula de sujeción, de tal manera que cuando por aplicación de los convenios o la decisión 578 tengamos la potestad exclusiva de gravar determinada renta y la misma no se encontrara gravada en nuestro país, se pueda activar esta cláusula a efectos de que en Perú se produzca tributación efectiva.

- Revisar los regímenes especiales como las exoneraciones e inafectaciones que pueden ser utilizadas para la creación de supuestos de doble no imposición. 


\section{CONCLUSIONES}

- Los Estados al ser países soberanos, establecen la implementación de un sistema tributario adecuado al país, situación que en algunos casos lleva a conflictos de tributación, dando origen a una doble o múltiple tributación internacional e incluso una doble no imposición.

- La doble no imposición es un fenómeno que se origina por la aplicación de los convenios para evitar la doble imposición, como producto de la asimetría de las diferentes legislaciones tributarias de los Estados que las firman.

- Si un Estado contratante tiene la potestad tributaria de gravar una determinada renta en virtud de un convenio, pero no la ejerce por diferentes motivos, no significa que el otro Estado contratante tenga en forma automática la potestad de gravar dicha renta, en este supuesto se originó el fenómeno de la doble no imposición.

- La celebración de los convenios tiene como propósito evitar la doble imposición, sin embargo haciendo uso de algunos vacíos en los mismos se han creado oportunidades de doble no imposición.

- La OCDE, a través de plan de acción BEPS ha elaborado informes que contienen medidas que permiten combatir la erosión de la base imponible y traslado de beneficios, y con el plan de acción 6 buscar hacer frente al fenómeno de la doble no imposición. 


\section{REFERENCIAS}

Ault, Hugh J. (1997). Comparative Income Taxation: A Structural Analysis. Kluwer Law International, Holanda.

Bassallo Ramos, C. (2008). El método de imputación para evitar la doble imposición en el CDI. Convenios para evitar la Imposición Tributaria. Grupo IFA, Lima.

Braccia, Mariano F. (2012). Interpretación y argumentación en el Derecho Tributario. Homenaje al 40 aniversario de la Carrera de Especialización de Derecho Tributario de la Facultad de Derecho de la Universidad de Buenos Aires. Ad hoc, Buenos Aires.

Braccia, Mariano F. (2016). Derecho Internacional tributario, el surgimiento de un nuevo orden de tributación internacional a partir del proyecto BEPS. Fondo Editorial de Derecho y Economía, Buenos Aires.

Bravo Cucci, J. (2006). Fundamentos de Derecho Tributario. Palestra Editores, Lima.

Bravo Cucci, J. (2013). Derecho Tributario-reflexiones. Jurista Editores, Lima.

Calderón Carrero, J. M. (1997). La doble imposición internacional y los métodos para su eliminación. McGraw-Hill, Madrid.

Calderón Carrero, J. M. (2004). Comentarios a los convenios para evitar la doble imposición y prevenir la evasión fiscal concluidos por España. Fundación Pedro Barrié de la Maza, Coruña.

Calderón Carrero, J. et al. (2005). Convenios fiscales internacionales. CISS, Valencia.

Castro Valdez, R. (2012, 19 de octubre). La doble no imposición en el marco de los CDI. Recuperado de http://smartpymes.com/ergaomnes/?p=24.

Condon, B. (2007). Curso sobre el Derecho de la OMC. ITAM, México.

Córdova, A. (2008). "Imposición a la renta sobre inversiones peruanas en el Exterior". En X Jornadas Nacionales de Tributación. IFA Grupo Peruano, Lima.

Danon, R. J. y Salome, H. (2004). Ëlimination de la doublé non-imposition en tant qu,objet et but des CDI (Rappoteurs du Groupement Suisse). Cahiers IFA. Vol. 89.

Díez de Velasco, M. (1994). Instituciones de Derecho Internacional público. 10ª edición, Tecnos, Madrid.

Escobar Honorio, B. et al. (2012). Operaciones con no domiciliados y convenios para evitar la doble imposición. El Búho, Lima. 
García Mullin, R. (1980). Impuesto sobre la renta; teoría y técnica del impuesto. Secretaría de Estado de Finanzas, Instituto de Capacitación Tributaria, Santo Domingo.

Gildemeister Ruiz-Huidobro, A. (2000). "La revolución del comercio electrónico y la tributación: la crisis del principio de territorialidad y los criterios de conexión tradicionales en el Derecho Tributario internacional”. Themis. Época 2, $\mathrm{N}^{\circ} 41$, Lima.

Grageda Núñez, E. (2010). "La interpretación de los tratados para evitar la doble tributación, el modelo de la OCDE y sus comentarios". Revista de Derecho Económico Internacional. Vol. 1, 우 1, México.

Grozzo Costa, L., Picón Gonzáles. (2008). "Situaciones de nula imposición en rentas pasivas a la luz de las normas de la decisión 578 de la CAN". En: Asociación Fiscal Internacional (IFA) Grupo Peruano. CDIs - Convenios para evitar la doble imposición. IFA, Lima.

Instituto de Estudios Fiscales. (2004). Manual de fiscalidad internacional. Solana e Hijos, A.G., Madrid.

García-Herrera Blanco, C. (coordinadora). IV Encuentro de Derecho Financiero y Tributario ( $3^{\mathrm{a}}$ parte). Doc. $\mathrm{N}^{\circ}$ 15/2016. Instituto de Estudios Fiscales, Madrid.

Lenz, K. (1960). "Sistemas internacionales de tributación". Cahiers de Droit Fiscal International. Vol. 75, b), Kluwer, Deventer.

Morris Guerinnoni, Alex. (2006). "Comentarios sobre la tributación de los no domiciliados en el Impuesto a la Renta”. En: Temas de Derecho Tributario y de Derecho Público. Libro homenaje a Armando Zolezzi Möller. Palestra, Lima.

Nuñez, F. (2010) Instrumentos financieros híbridos - Aspectos tributarios derivados de la distinción entre "instrumentos de deuda" e "instrumentos de capital" y criterios de clasificación aplicables a este tipo de instrumentos. IPDT, Lima

Organización para la Cooperación y el Desarrollo Económicos. (2014). Plan de acción contra la erosión de la base imponible y el traslado de beneficios. OCDE. Recuperado de http://www.aedfifa.org/FicherosVisiblesWeb/Ficheros/Fichero79.pdf.

Reig, E. ; Gebhardt, Rubén; Malvitano, Rubén H. (2006). Estudio teórico-práctico de la ley argentina sobre impuesto a las ganancias a la luz de la teoría impuesto a la renta. $11^{\mathrm{a}}$ edición, Macchi, Buenos Aires.

Revista de Fiscalidad Internacional y Negocios Transnacionales.2017, № 4 (eneroabril).

Ring, Diane M. (2007). “International Tax Relations: Theory and Implications”. Tax Law Review. Vol. 60. 
Rubio Guerrero, J. J. (2002). "Los principios básicos de la fiscalidad internacional y la doble imposición internacional". En: Instituto de Estudios Fiscales. Manual de Fiscalidad Internacional. Ministerio de Hacienda, España.

Serrano Antón, F. Hacia una reformulación de los principios de sujeción fiscal. Doc. $\mathrm{N}^{\circ} 18 / 06$, Instituto de Estudios Fiscales, Madrid.

Sol Gil, J. (2006). "Alcance general, impuestos cubiertos y definiciones en los convenios de doble imposición". En: Estudios de Derecho Internacional tributario: los convenios de doble imposición. Instituto Colombiano de Derecho Tributario, Bogotá.

Sotelo Castañeda, E. (1999). “Doble imposición internacional”. Ius et Veritas. № 19.

Tillinghast, D. R. (1984). “A matter of definition: Foreing and Domestic Taxpayers". Int'l Tax \& Bus. Law. Vol. 2.

Uckmar, V. (2003). Los tratados internacionales en materia tributaria en Curso de Derecho Tributario Internacional. Tomo I. Temis, Bogotá.

Villagra, R. (2008). "Los convenios para evitar la doble imposición y prevenir la evasión fiscal. Con énfasis en los convenios vigentes en el Perú". En: Asociación Fiscal Internacional (IFA) Grupo Peruano. CDIs - Convenios para evitar la doble imposición. IFA, Lima.

Xavier, A. (s.f) "Doublen non Taxation". Cahiers de droit fiscal internacional - IFA. Vol. 89.

Zuzunaga del Pino, F. (2008). "Convenios para evitar la doble imposición”. En: IX Jornada Nacional de Tributación. IFA, Lima. 